\title{
A Systematic Review of Psychosocial Explanations for the Relationship Between Socioeconomic Status and Body Mass Index
}

\author{
Maria Almudena Claassen ${ }^{1}$, Olivier Klein ${ }^{1}$, Boyka Bratanova ${ }^{2}$, Nele Claes ${ }^{1}$, Olivier \\ Corneille ${ }^{3}$
}

\author{
${ }^{1}$ Université Libre de Bruxelles \\ ${ }^{2}$ University of St. Andrews \\ ${ }^{3}$ Université catholique de Louvain
}

Appetite, 2018

Author Note

Correspondence concerning this article should be addressed to (Maria) Almudena Claassen, Université Libre de Bruxelles, 50 av. F.D. Roosevelt, B-1050 Brussels, Belgium. Tel: +32(0)26506787 / Email: mclaasse@ulb.ac.be.

No potential conflict of interest was reported by the authors.

This work was supported by a grant of the Walloon Region (Belgium, FOOD4GUT, project \#1318148). 


\begin{abstract}
A negative association between socioeconomic status (SES) and levels of overweight/obesity is consistently found in high- and middle-income countries. Yet, there is little conclusive evidence about the mechanisms driving this association. In this systematic review, we discuss and compare the results of 22 studies that examine the role of psychosocial mediators in the association between lower SES and BMI in diverse population samples. These include factors related to resources and constraints in one's external neighborhood, social resources, and psychological factors such as stress. The findings support theoretical models indicating that SES influences BMI partially through environmental and psychological factors. Importantly, SES remains a significant determinant of weight status, indicating the importance of also addressing structural antecedents in order to improve health among low-SES people. We thoroughly discuss the quality and limitations of current study designs and mediation testing and provide recommendations for future research.
\end{abstract}

Keywords: socioeconomic status, obesity, BMI, psychosocial, systematic review 
Levels of overweight and obesity have reached alarming numbers worldwide. In 2016, $39 \%$ of adults were overweight and 13\% were obese (WHO, 2017b). Data from 2015 shows that obesity prevalence was highest in the US: $35 \%$ for adult men and $40 \%$ for adult women (OECD, 2017), and 15\% within EU countries in 2014 (Eurostat, 2014). People who are overweight are at increased risk of suffering from cardiovascular diseases (CVDs), diabetes, musculoskeletal disorders and some cancers, with CVDs being the leading cause of death globally, responsible for an estimated 17.7 million deaths in 2015 (WHO, 2017a).

Socioeconomic status (SES) is negatively correlated with weight status in high- and middle-income countries (Dinsa, Goryakin, Fumagalli, \& Suhrcke, 2012; Robertson, Lobstein, \& Knai, 2007; Wang \& Beydoun, 2007). Food production and availability is more advanced in relatively wealthier countries, and people with lower incomes can afford highcalorie foods (Pampel, Denney, \& Krueger, 2012), leading to an excess of calorie intake, with higher risk of becoming overweight or obese (Tanumihardjo et al., 2007). A systematic review in 2010 indicated that whereas the obesity epidemic is leveling off in some countries, this is less the case for individuals with lower SES (Rokholm, Baker, \& Sørensen, 2010).

Scholars commonly point to limited access to healthy foods as the cause of higher obesity rates among lower SES people. Material deprivation is seen as the primary cause, with limited financial resources and limited food availability restricting access to healthier diets (Aggarwal, Monsivais, Cook, \& Drewnowski, 2011; Story, Kaphingst, RobinsonO’brien, \& Glanz, 2008). However, a nutritious diet does not need to cost more than a less nutritious diet, notably in European countries (Carlson \& Frazão, 2014; Primavesi, Caccavelli, Ciliberto, \& Pauze, 2015), and programs reducing the financial cost of healthy foods through food vouchers or tax reductions show unsubstantial effects on nutrition and weight outcomes (Capacci et al., 2012; Powell \& Chaloupka, 2009; McFadden et al., 2014). Likewise, supermarket density is high in Europe making a variety of food outlets easily 
accessible (Black \& Macinko, 2008; Cummins \& Macintyre, 2006; Fleischhacker, Evenson, Rodriguez, \& Ammerman, 2011). And two recent publications showed that in the U.S., neither actual nor perceived availability of (fast) food outlets was related to fast food consumption (Oexle, Barnes, Blake, Bell, \& Liese, 2015) or BMI (Mejia, Lightstone, Basurto-Davila, Morales, \& Sturm, 2015).

These findings suggest that there must be other factors besides those directly associated with material deprivation that influence the weight status of people with lower SES. Previous reviews examining SES-weight associations find more evidence for a social gradient in obesity among women than among men, and suggest explanations related to cultural and symbolic values of body shape (McLaren, 2007; Sobal \& Stunkard, 1989). The pressure to be thin is highest for women on the top end of the SES spectrum: While larger female body shapes are subject to stigmatization, larger sizes in men are associated with power and dominance (Fikkan \& Rothblum, 2012; McLaren, 2007). This is, for instance, apparent in work settings where men with higher incomes work more hours and exercise less, whereas women with higher incomes exercise more often (Godley \& McLaren, 2010).

Furthermore, the stigmatization of one's lower social status as well as the stigma associated with a larger body size can result in more negative emotions and cortisol secretion which promote the intake of high-calorie foods (Tomiyama, 2014; Vartanian \& Porter, 2016). This is also evident in epidemiological findings indicating that regardless of absolute income levels, obesity prevalence is higher in countries with more income inequality (Pickett, Kelly, Brunner, Lobstein, \& Wilksinon, 2005). And recent research shows that mere activation of lower relative social position leads to higher calorie intake (Cheon \& Hong, 2017; Sim, Lim, Forde, \& Cheon, 2018). Stress-induced weight gain due to insecure economic conditions has been proposed as one of the central mechanisms through which lower SES leads to increased body weight. For instance, restricted food access (in early life) is associated with metabolic 
changes that encourage the storage of body fat (Nettle, Andrews, \& Baton, 2017). Similar bodily changes, as well as shifts towards a preference for high-calorie foods, occur due to chronically elevated stress levels associated with financial insecurity (Baum, Garofalo, \& Yali, 1991; Moore \& Cunningham, 2012).

The work discussed above addresses possible pathways through which a social gradient influences weight. However, to date there is a lack of a comprehensive review on such mediating pathways. The current contribution was aimed to fill this gap by providing a systematic review of psychosocial mediators of the SES-BMI relation.

Broader theoretical models on the SES-health link can provide us with a framework for clarifying pathways linking SES with weight status. Such models describe pathways by which macro-level contexts, social environments, and individual psychological and biological characteristics increase risk of illness (Adler \& Ostrove, 1999; Gallo \& Matthews, 2003; Martikainen, Bartley, \& Lahelma, 2002). According to these models, individuals with lower SES experience more environmental and social disadvantage which are constraints to health and well-being (pathway A in Figure 1). Financial stress lowers psychological resources to cope with adversity which in turn impedes health (pathway B in Figure 1). Furthermore, environmental demands and social resources can shape cognitive and affective tendencies, thereby determining the extent to which an individual will experience stress in response to subsequent stressors (see pathway C in Figure 1; Adler \& Ostrove, 1999; Adler \& Snibbe, 2003). Both environmental and psychological factors then influence illness through biological responses, exposure to health risks, and health behavior performance. Review papers have illustrated that the pathways suggested by these models indeed partially explain social gradients in health such as mortality and cardiovascular health (e.g., Gallo \& Matthews, 2003; Matthews, Gallo, \& Taylor, 2010). 


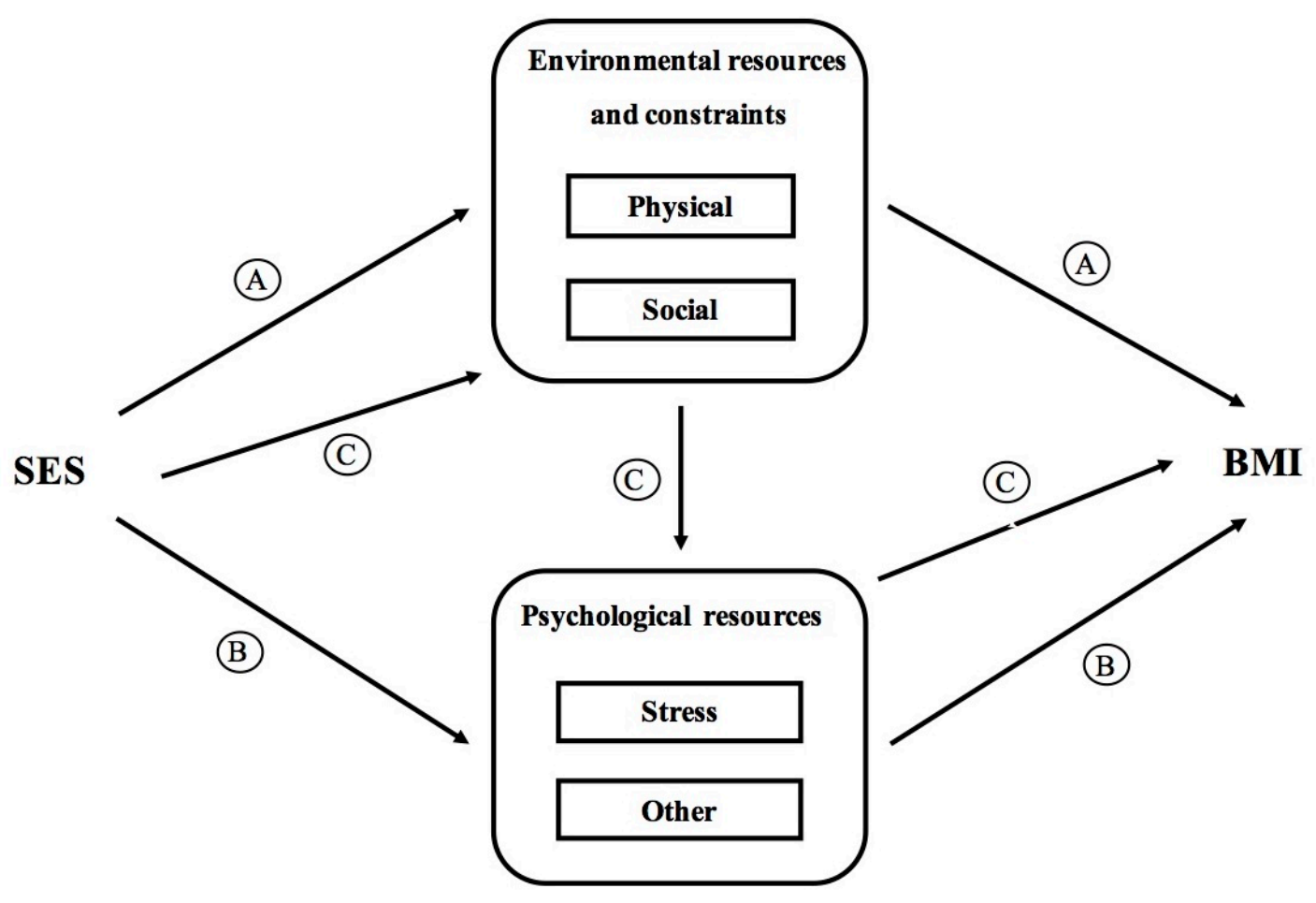

Figure 1. Model of suggested pathways from socioeconomic status to BMI. Adapted from Adler and Ostrove (1999). Pathway A links SES with BMI through environmental factors, pathway B through psychological factors, and pathway $\mathrm{C}$ through a combination of environmental and psychological factors.

\section{Objective of the Current Review}

The main objective of this article is to provide a review of existing publications examining psychosocial pathways underlying the relationship between SES and weight status. In line with the theoretical propositions described above, the broad term psychosocial refers to individual-level environmental and psychological factors (Adler \& Ostrove, 1999; Martikainen et al., 2002). Identifying the pathways that link SES with weight status allows targeted interventions for public health improvement to be developed. Beyond examining the contribution of suspected mediators, the present review will also systematically discuss the strengths and weaknesses of current research in this health domain. More specifically, this 
review will propose an assessment of the conclusiveness of designs and statistical tests used for examining these psychosocial pathways. This assessment, in turn, will allow making recommendations for future research, as proposed in the general discussion.

\section{Method}

This review followed the Preferred Reporting Items for Systematic Reviews and Meta-Analyses (PRISMA; 2009) guidelines for systematic reviews. The search strategy was pre-registered in PROSPERO (International Prospective Register of Ongoing Systematic Reviews, http://www.crd.york.ac.uk/prospero) under registration number: CRD42017068926).

\section{Search Strategy}

In order to find relevant published research examining psychosocial explanations of the relationship between lower SES and weight status, we searched Scopus and PsycINFO databases. We created a string of search terms related to SES, psychosocial factors, and weight. To make sure the studies included examination of a psychosocial pathway, we restricted our search to articles that also included the terms 'psychosocial' or 'psychology'. The complete search string was ('socioeconomic' or 'income' or 'education' or 'poverty' or 'inequalit*' or 'depriv*' or 'disadvantage*' or 'social class' or 'poor' or 'rich') AND ('psycholog*' or 'psychosocial' or 'psycho-social') AND ('obes*' or 'BMI' or 'weight'). We restricted the search to terms appearing in the title, abstract, and keywords of publications.

\section{Inclusion and Exclusion Criteria}

A systematic review of the relevant literature was conducted according to the following inclusion and exclusion parameters. Studies were only included if they included a measure of SES, a psychosocial measure of environmental or psychological nature (e.g., food availability, a measure of stress), and a measure of BMI.

SES (independent variable): In our selection of articles, we considered both objective 
SES indicators such as income and occupation, and subjective measures of SES such as perceived social position. We included studies that used an indicator of SES as an independent variable, comparing differences between SES groups, and excluded those that exclusively focused on low SES groups (no mediation could be possibly tested in these studies due to a lack of variance in the predictor) and those that merely controlled for SES.

Psychosocial resources and constraints (mediator): these are addressed in the next section.

BMI (dependent variable): The studies needed to assess weight status using BMI as an indicator. The study was also included if obesity status was used as a dependent variable, as long as this status was determined by a measure of BMI. BMI is derived from an individual's weight and height $\left(\mathrm{kg} / \mathrm{m}^{2}\right)$. A person is considered overweight if his or her BMI falls between 25 and 30, and obese if this value is above 30 (standards used by the National Institutes of Health, 2000). It is the most commonly used measure, easily derived and considered an adequate measure for clinical purposes (Mooney, Baecker, \& Rundle, 2013).

We included studies using the following designs and methods of mediation testing. Design: Different study designs allow for testing causal and mediational relationships between variables. We included articles using one of the following methods: 1) manipulation of a psychosocial factor that is typically assumed to be influenced by SES, followed by a measure of BMI and SES. This provides the best causal evidence (Bullock, Green, \& Ha, 2010; Spencer, Zanna, \& Fong, 2005), or random assignment to different SES groups, followed by a measure of a psychosocial factor and BMI, 2) cross-lagged panel design with repeated measures at different time points to control for changes over time and to allow for more precise inferences about the direction of causation (Cole \& Maxwell, 2003; Selig \& Preacher, 2009), 3) longitudinal design without repeated measures across time points (i.e., not 
cross-lagged), 4) cross-sectional design (See Figure 2 for a graphical presentation of this ranking of designs).

Studies examining other relationships between these variables, for instance, the moderating role of SES, or the influence of BMI on psychosocial factors and SES were excluded. On the other hand, studies whose results allowed for interpreting mediational pathways linking SES and BMI were included even if this was not the focus of the study.

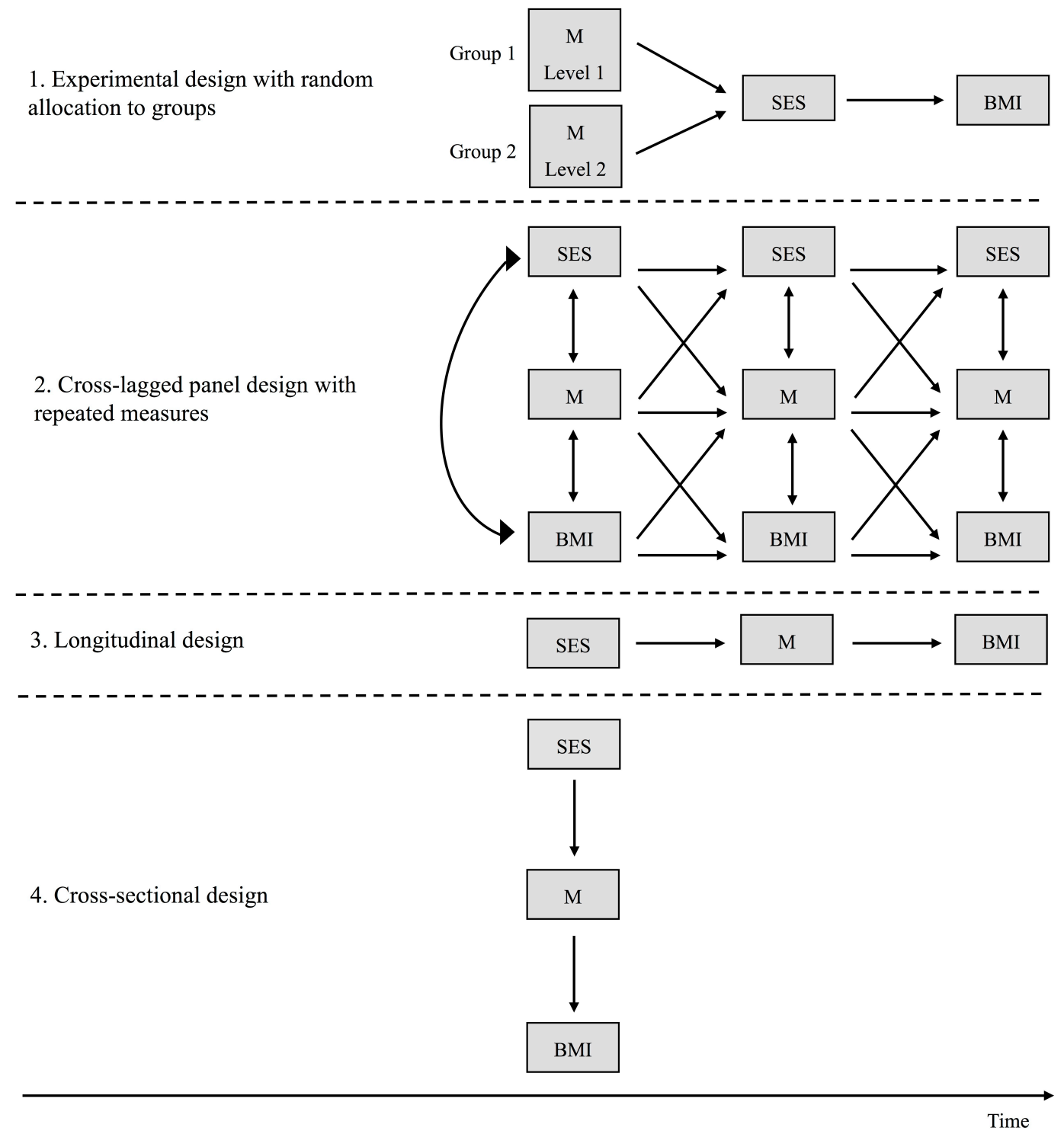


Figure 2. Criteria for inclusion of study designs and level of experimental rigor. Variations within designs are possible. $\mathrm{SES}=$ socioeconomic status, $\mathrm{M}=$ psychosocial mediator, $\mathrm{BMI}=$ Body Mass Index.

Mediation test: The studies examining psychosocial explanations of the relationship between SES and BMI needed to test for mediational pathways between these variables. There are different ways of testing mediation and we included studies that, as a minimum, used coefficient testing (MacKinnon, Lockwood, Hoffman, West, \& Sheets, 2002). Figure 3 shows an overview of different levels of analysis that can be used to test for mediation.

\section{Level}

1 Coefficient tests: comparing the influence of SES on BMI before and after inclusion of a mediator (e.g., MacKinnon et al., 2002).

2 Causal steps approach: at least testing two steps, including the influence of SES on the mediator and the mediator on BMI (Baron \& Kenny, 1986; Cohen \& Cohen, 1983).

3 Testing statistical significance of the indirect path (e.g., product of coefficients approach; Sobel, 1982, bootstrapping; MacKinnon, Lockwood, \& Williams, 2004).

$4 \quad$ Examining alternative mediators by comparing different indirect effects (e.g., Preacher \& Hayes, 2008a).

$5 \quad$ Testing alternative order of variables to establish causality (e.g., Smith, 1982).

Figure 3. Ordering of least to most reliable analysis for establishing mediation. The levels are cumulative.

Included articles were published within the last 20 years (from 1997) and were written in English. Excluded were studies that focused on undernutrition or studies carried out in countries where a positive relationship between SES and BMI is found (typically in lowerincome countries; Dinsa et al., 2012). Additional exclusion criteria were non-human or clinical samples (e.g., anorexia, diabetes, pregnancy, but obesity studies were included), and 
studies involving children because the association between their SES and weight status is dependent on their parents' behaviors (Shrewsbury \& Wardle, 2008). However, longitudinal studies in which measurements were taken during adulthood as well as during childhood were included.

\section{Identification of Relevant Publications}

Article screening followed the PRISMA guidelines (Moher, Liberati, Tekzlaff, \& Altman, 2009; see Figure A1 in Appendix A1 in the Supplemental Online Material for a flow-diagram and Table A2 in Appendix A2 for the PRISMA statement). The searches yielded 3015 hits. After removing the duplicates, 2631 were left. We first screened titles for relevant publications, 875 remained. Next, we screened abstracts, eliminating another 552 and leaving 323. After reading the full-text articles, 22 were selected for inclusion in the review. Reasons for discarding the articles after reading the full-text were mostly due to not using BMI as a dependent variable, or not assessing mediation (for both reasons $26 \%$ of articles were discarded). The reference list of reviews found through this search was searched laterally but this did not yield any relevant hits.

\section{Classification of Mediators and Assessment of Mediation}

Two independent researchers classified the measures used in the included articles according to the categories proposed by the theoretical models discussing psychosocial explanations for the relationship between SES and health (e.g., Adler \& Ostrove, 1999): environmental and psychological resources and constraints. Environmental factors included those associated with 1) the external and physical environment such as perceptions of environmental disorder and control, and 2) the social environment, such as social support and community involvement. Psychological factors included 1) affective, and 2) cognitive processes. In our classification we did not distinguish between affective and cognitive factors because their components overlap (e.g., Oatley, Keltner, \& Jenkins, 2006). Nevertheless, we 
classified factors as "stress-related" if they measured perceived stress or negative emotions, and "other" if assessing other psychological resources and constraints. Psychological factors were included if they were assessed with questionnaire-based methods and not by physiological measurements. For instance, stress was considered a psychosocial mediator if assessed by a question regarding an individuals' experience of stress in the past 30 days, but not by a measure of blood cortisol level, which we consider a physiological factor.

Discrepancies in the classification of factors by the two researchers were resolved through discussion, with the help of a third researcher when necessary.

\section{Assessment of Empirical Conclusiveness}

Each of the studies included in this review was subjected to an assessment for drawing reliable conclusions about the existence of mediation. We developed a scoring system based on the different levels of design and levels of mediation test outlined in the inclusion/exclusion criteria. Based on these levels, studies could score four points for design (D1_4), and five for mediation test (M1_5). Table 1 shows the classification of the included studies according to these criteria. For points regarding M1_5, please note that these were taken as cumulative: A score of M5 means that criteria M1 to M4 have been met.

Due to the small number of studies assessing statistical significance of mediation, we did not require this as evidence for supporting mediation. Moreover, we concluded that there was support for mediation regardless of whether there was complete or partial mediation, and regardless of whether the direct effect of SES on BMI was significant (Mackinnon, Krull, \& Lockwood, 2000; Zhao, Lynch Jr., \& Chen, 2010). The results were analyzed in terms of support for mediation of the relationship between SES and BMI through the different psychosocial pathways proposed by the theoretical models (see pathways A, B and C in

Figure 1). Some studies measured psychosocial factors which were not tested as mediators 
(i.e., such as in path analysis models in which a specific factor was not allowed to predict BMI directly). If mediation was not assessed, it was not discussed in our result section.

[Insert Table 1 about here]

\section{Results}

A total of 22 studies that met the criteria were identified. The studies differed in the types of mediators tested, with $60 \%$ of them examining both an environmental and a psychosocial factor, $32 \%$ - a psychosocial factor, and 9\% - an environmental factor (the classification of factors measured in each study can be found in Appendix C1 in the Supplemental Online Material, and Table D1 in Appendix D1 in the Supplemental Online Material provides a summary of the important characteristics of the included studies).

The studies reviewed revealed distinct associations between SES, psychosocial factors, and BMI across genders. Firstly, when considering all different SES indicators assessed across studies, in $67 \%$ of cases these indicators were significantly related to women's weight. Among men, this was the case for $51 \%$ of the indicators used. A significant association between income and weight was more often found among women ( $89 \%$ vs. 44\% among men, in the articles that assessed income as an indicator of SES). In contrast, among both genders, education was frequently related to weight (66\% among men and $75 \%$ among women) while employment status was not (around $20 \%$ for both genders) ${ }^{1}$. This corroborates

\footnotetext{
${ }^{1}$ These results need to be taken with caution as not all articles assessed the influence of the predictors on BMI without simultaneously controlling for other predictors, and not all articles specified results for men and women separately. It should also be noted that in some studies the relationship between SES and BMI did not follow a linear function (e.g., Guthrie, Lessl, Ochi, \& Ward, 2013 - \#9), while others found a positive relationship between SES and weight (e.g., in men; Matheson et al., 2008 - \#14).
} 
findings in the literature showing that the relationship between SES and weight status is negative and consistent among women, but inconsistent or non-significant among men, depending on the SES indicator used (Mclaren, 2007; Sobal \& Stunkard, 1989).

The empirical conclusiveness scores for the studies were considerably low, with $27 \%$ of studies falling in the weakest category (D1*M1; see Table 1$)$. The types of designs and mediation tests used both contributed to this relatively low score. Thirty-two percent of studies used a longitudinal (but never a cross-lagged) design, and 68\% used a cross-sectional design. Moreover, among the included studies, 36\% performed coefficient testing, and 63\% assessed (at least) the relationship between SES and a psychosocial mediator, and the relationship between a mediator and BMI. However, only 35\% among those assessed statistical significance of mediation or compared the relative strength of direct and indirect pathways linking SES and $\mathrm{BMI}^{2}$.

In $51 \%$ of the studies, there was support for (partial) mediation of the relationship between SES and BMI through psychosocial factors. Of the studies examining environmental factors (pathway A), 44\% found support for (partial) mediation, which was lower than that for psychological factors (57\%; pathway B). Based on the included studies, the results provided the most support for mediation through psychological factors (unrelated to stress). Seventy-eight percent of these studies found support for (partial) mediation (versus $36 \%$ -

\footnotetext{
${ }^{2}$ Important to note, however, is that the scoring was based on the analysis performed regarding the relationship of interest to the current paper. For instance, some studies scored only M1 for their mediation test of the SES-BMI relationship, whereas they did test for the significance of a different mediation pathway (associated with a score M3). These studies were, for instance, interested in pathways linking SES with disease inflammation markers, through psychosocial factors and BMI.
} 
$57 \%$ for physical, social, and stress-related factors). Furthermore, $60 \%$ of the studies examining the influence of both environmental and psychological factors (pathway C) in the relationship between SES and BMI found support for (partial) mediation. See Figure 4 for a graphical representation of the percentage of suggested support for mediation across studies.

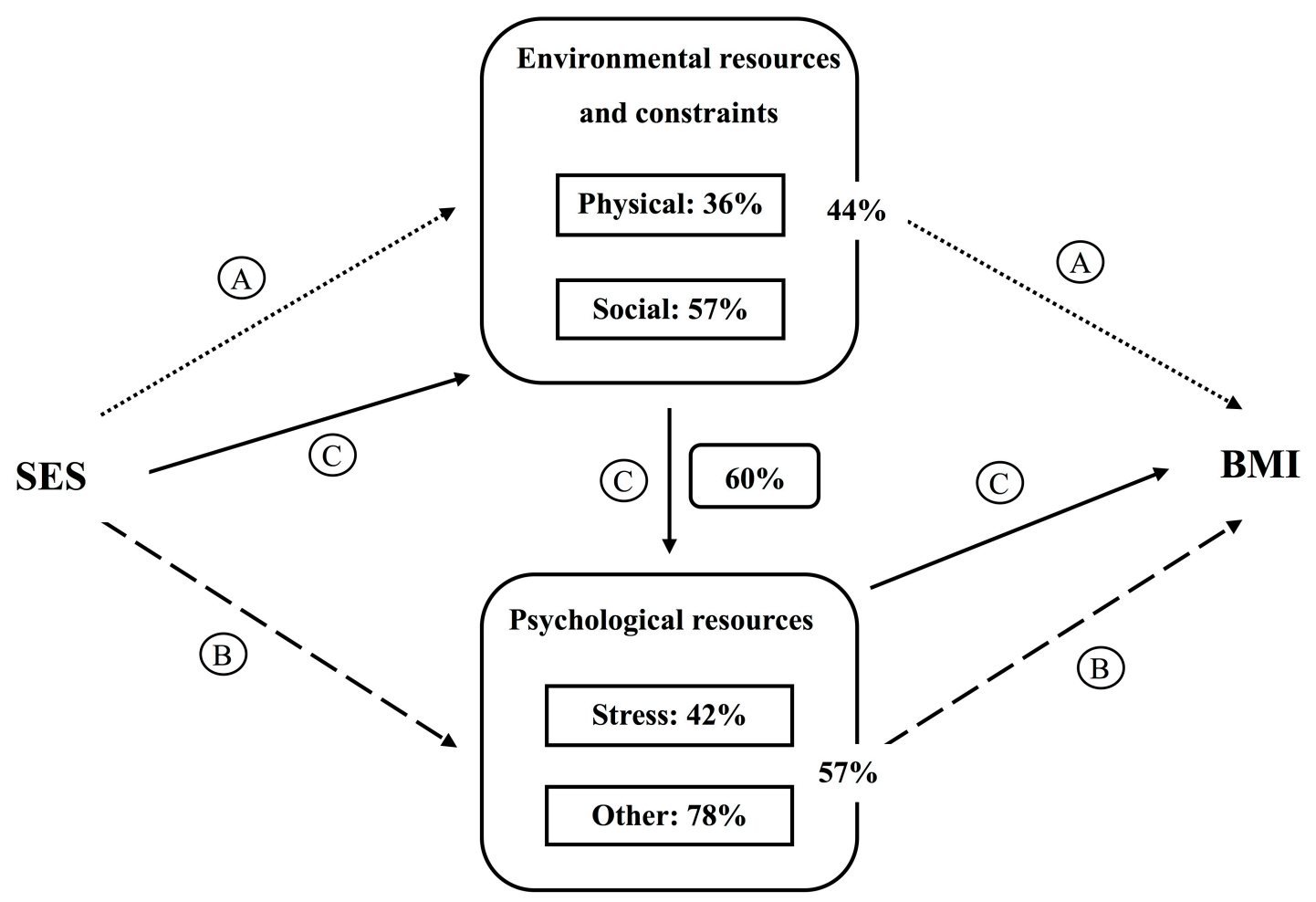

Figure 4. Overview of the percentage (\%) of support for each pathway and psychosocial mediator assessed in the reviewed studies. The more dashed the line, the less consistent the evidence.

\section{Results of Pathways Linking SES with BMI}

Studies examining environmental resources and constraints (pathway A). Ten studies included in this review examined environmental factors as mediators of the relationship between SES and BMI. Among these, eight assessed physical factors, and seven social resources. 
Physical factors. Five studies examined factors related to their neighborhood or community (\#4, \#11,\#12,\#16,\#17) and one - food insecurity (\#3). Furthermore, three studies assessed job factors (\#2, \#15,\#20), and four - stress related to the home and school environment in young adulthood (\#13, \#15, \#18, \#21).

From the five studies examining the mediating role of neighborhood factors, one found no support for mediation (\#17), and two only through indirect pathways with social support (\#11,\#12; see results for social factors), or with negative affect (\#12; see results for pathway C). Among the studies that did find support for mediation, a cross-sectional multilevel analysis $(\mathrm{D} 1 * \mathrm{D} 1)$ of objectively measured community disadvantage showed that more disadvantage was related to higher BMI in women and that it slightly reduced the association between lower income and BMI, but not that between lower education and BMI (\#16). However, this study scored low on our assessment of empirical conclusiveness and assessed self-reported, not measured, BMI. A longitudinal study (D2*M4) found that poorer neighborhood quality was related to higher BMI and obesity and that it reduced the association between subjective SES and overweight, simultaneously controlling for objective measures of SES (\#4). Nevertheless, addition of childhood SES factors, which included adolescent neighborhood quality, eliminated the significant association between low current neighborhood quality and BMI, and reduced that with obesity.

The study $(\mathrm{D} 1 * \mathrm{M} 4)$ examining the role of food insecurity found that SES was inversely associated with food insecurity. Food insecurity had no direct association with BMI, except through psychological factors (\#3; see results for pathway C).

There was little evidence that work stressors, and childhood stressors related to home and school played a role in the relationship between SES and BMI. One study (D1*M2) showed that in a sample of women, lower social position was associated with higher job strain, and that higher job strain was associated with obesity although not with BMI (\#20). 
Job strain accounted for about $18 \%$ of the association between lower SES and obesity, but this was lower than the amount explained by two psychological resources (self-esteem and expectations for the future which individually accounted for $23 \%$ and $34 \%$, respectively; see results for pathway B). The two other studies found no mediation by high job demands or low job control on the relationship between SES and BMI (\#2, \#15), although one study (D1*M1) did find that skill discretion (skill and creativity required and flexibility in using these skills at work) was inversely related to BMI (\#2).

Another study (D2*M1) tested whether childhood stressors explained educational differences in overweight (\#15). Among women but not among men, childhood stress related to home (parental divorce) and school (low control and unpopularity) reduced the association between lower education and overweight/obesity at age 30 by at least $10 \%$ (\#15). Among men, only low parental social support in education explained a significant part $(29 \%)$ of the association between lower education and later overweight risk in men. The other three studies examining childhood factors did this only in path analyses together with psychological factors (\#13,\#18, \#21; see results for pathway C).

Social factors. Evidence for social resources as a mediator in the relationship between SES and BMI was inconclusive based on the findings from seven studies that found mixed results in terms of type of social factors assessed, the strength of the mediation, and the direction of the relationship between social resources and BMI. Most studies examined social support as number of close friends, or satisfaction with one's social relations (\#1, \#11, \#12, $\# 15, \# 16, \# 20)$. Other measures used were sense of belonging (\#14) and participation in social activities related to an association (\#15).

Three out of seven studies found no evidence that social factors mediated the association between SES and BMI (\#14, \#16,\#20). One study (D1*M1) found that weak versus strong community sense of belonging was related to higher BMI but had no influence 
on the association between lower education and BMI (\#14). Four studies did find that social support mediated (part of) the association between SES and BMI (\#1, \#11,\#12,\#15). Two of these studies were carried out in the same laboratory (\#11,\#12). Using structural equation modeling (SEM; D1*M4) they both found a significant indirect pathway showing that SES was positively related to social support, and that there was a positive association between social support and BMI. Furthermore, there was also a significant indirect relationship including neighborhood disadvantage: SES was inversely associated with perceived neighborhood disadvantage, which was in turn inversely associated with social support.

On the contrary, a study (D2*M1) examining the cumulative influence of adverse circumstances in adolescence and young adulthood on adult BMI, found that perceived availability of a social network and social support did not explain any variance in the relationship between education and overweight (\#15). However, not participating in social activities at age 30 explained $29 \%$ of the increased risk in overweight of lower educated men. OR adjustments were tested separately for each mediator and then together in a cumulative model showing that parental support in adolescence was a more important factor than participation in social activities.

Surprisingly, several studies revealed that possessing greater social resources was associated with higher levels of BMI/obesity (\#1, \#11, \#12, \#14). For instance, whereas in an overweight/obese sample, support for exercise was inversely associated with BMI, there was a positive association between support for healthy eating and BMI (\#1). However, social support was inversely associated with calorie consumption, which suggests a reverse causal pathway between social support and weight: The more obese individuals receive more support from their social environment, rather than their weight being influenced by the amount of social support they receive. Table 2 shows an overview of the findings regarding environmental factors. 
[Insert Table 2 about here]

Studies examining psychological resources and constraints (pathway B). Eighteen studies examined the influence of psychological factors in the relationship between SES and BMI. Thirteen among these examined stress-related factors and seven other psychological processes.

Stress-related factors. Thirteen studies examined the influence of perceived stress, negative affect, or a combination of both, of which one only in SEM models together with environmental factors (\#21; see results for pathway C). The factors examined were, among others, negative life events, negative affect, and depressive symptoms.

Five studies out of twelve found that factors related to stress mediated (part of) the relationship between SES and BMI (\#4, \#5, \#8, \#10,\#22). The others did not (\#11, \#13,\#14, $\# 16, \# 17)$, or only in an indirect pathway with environmental factors (\#3, \#12; see results for pathway C).

Two studies found a negative relationship between stress and BMI. One study (D2*M4) showed that higher stress experienced in the last 30 days, simultaneously controlling for depressive symptoms, was related to lower BMI and obesity and explained a statistically significant $18.2 \%$ of the relationship between subjective social status and BMI (\#4). Depressive symptoms were not associated with BMI. Results were identical with obesity status as a dichotomous dependent variable. The second study (D2*M2) examined associations between childhood and adult SES on BMI, and assessed a composite measure reflecting stress related to environmental, social, psychological and physical domains (\#10). There was a significant negative association between SES and stress, and SES and BMI, but stress was not associated with BMI.

The other studies found that experiencing more stress was associated with higher BMI $(\# 3, \# 5, \# 8, \# 21, \# 22)$. One of these studies $(D 1 * M 3)$ showed that of the three stress measures 
assessed, two partially mediated the association between low income and obesity, although the mediation was not statistically significant and the reduction was minimal: $3.3-5.1 \%(\# 8)$. This was similar to the $5 \%$ reduction found in another study (D1*M1; \#5). Two other studies revealed that controlling for stress in a linear regression model reduced the strength of association between income and BMI/obesity in women, but not in men (\#8, \#22).

Other psychological factors. Seven studies examined the influence of other psychological resources and constrains, including time perspective/future expectations (\#9, $\# 20$ ), eating motivation and control (\#1, \#7), personal control (\#4,\#19,\#20), and personality characteristics (\#4, \#6).

People differ in the extent to which they are more focused on their present or future, with low SES being associated with a present-oriented focus (Fieulaine \& Apostolidis, 2015). A present-oriented time perspective is associated with unhealthier behaviors and heavier weight status (Daugherty \& Brase, 2010; Dassen, Houben, \& Jansen, 2015). In one of the studies included in this review $(\mathrm{D} 1 * \mathrm{M} 2)$, neither present nor future time orientations mediated the relationship between education and overweight/obesity, nor were they associated with BMI (\#9). The second study (D1*M2) assessed people's expectations of the future by showing them a ten-grade ladder with the lower rung representing the worst possible expectation, and the $10^{\text {th }}$ rung the best possible expectation for the future (\#20). The researchers found that expectations of poor quality in one's future life accounted for approximately $34 \%$ of the association between low SES and obesity. Both studies were carried out in small samples $(\mathrm{n}<301)$.

Two studies found that part of the association between SES and BMI was accounted for by attitudes and motivations towards eating $(\# 1, \# 7)$. In a study with an obese sample (D1*M2), motivation for healthy eating was positively associated with BMI, but self-efficacy for exercise and healthy eating, assessed by questions regarding one's intentions to exercise 
and one's ability to control their eating, were not related to BMI (\#1). Another study $(\mathrm{D} 1 * \mathrm{M} 2)$ examined eating restraint, the extent to which people restrict their food intake to lose or maintain weight, eating disinhibition, a loss of eating restraint, and the extent to which one regularly experiences hunger (\#7). Only scores on the hunger scale (measured with items such as "I am always hungry enough to eat at any time"), but not on the restraint and disinhibition scale, differed across employment grades. Adjusting for hunger scores attenuated the mean difference in BMI across low vs. high employment grade by $8.4 \%$.

Evidence for the influence of personal control was mixed. In two studies, skills to cope with school/work responsibilities and social difficulties, or dealing with scarce financial situations were not associated with BMI or obesity (\#19, \#20). In the latter study (D1*M2), however, it was found that women with lower social positions reported less self-esteem, and this explained approximately $23 \%$ of the SES gradient in BMI, but this was not as much as negative expectations about one's future life which individually explained $34 \%$. Contrary to these findings, another study (D2*M4) found a positive association between mastery and BMI and obesity. Simultaneously controlling for personality characteristics in a regression model, these factors slightly reduced the coefficient of subjective SES as a predictor of BMI/obesity, although this reduction was not statistically significant (\#4).

Neither of the two studies examining personality characteristics found strong support for mediation, and the associations of each personality characteristic with BMI and obesity were different. Personality characteristics were assessed with the Big Five scales which consist of subscales assessing five different characteristics (Barrick \& Mount, 1991). The conclusion that can be drawn from these two studies is that personality characteristics are associated with weight status in different ways among men and women: For instance, in one study (D2*M1), higher scores on the agreeableness sub-scale, which assesses one's consideration of others, was related to higher BMI and obesity among men but not among 
women (\#6). On the contrary, in the other study $(\mathrm{D} 2 * \mathrm{M} 4)$ there was a negative association between agreeableness and BMI but not obesity (\#4). Furthermore, in both studies higher conscientiousness, one's tendency to be self-disciplined, was related to lower BMI/obesity among both men and women, reflecting the positive influence greater self-discipline can exert on health. These results, however, need to be interpreted cautiously since in both studies the internal consistency for the conscientiousness dimension was poor or questionable. Table 3 provides an overview of the results.

[Insert Table 3 about here]

\section{Studies examining psychological resources and constraints as a mediating}

\section{pathway between SES, environmental resources and constraints and BMI (pathway C).}

Thirteen studies measured both environmental and psychological factors, among which eight assessed mediation of the association between lower SES, environmental factors, and BMI $(\# 3, \# 4, \# 11, \# 12, \# 13, \# 16, \# 18, \# 21)$. Six among those used SEM or path analyses to examine significant pathways linking SES with BMI.

Results regarding the associations assessed were mixed with studies finding support for and against mediation of the relationship between SES, environmental factors and weight. For instance, a life-course analysis (D2*M2) illustrated that cumulative adversity in adolescence was positively associated to BMI in adulthood (\#21). This association was partially explained by a chain starting with parental rejection, depressive symptoms, and precocious life events during adolescent years (e.g., onset of sexual intercourse before 16 years). Yet, in another study (D2*M2), path analyses indicated that although material disadvantage in early life was positively associated with psychological distress through the quality of one's parental relationship at age 16 , there was no significant association between psychological distress and BMI (\#13). The study concluded that material factors were more important than psychosocial factors in translating childhood SES into poor health later in life. 
Another study using SEM (D1*M4) found that neighborhood disadvantage and social support mediated part of the influence of SES on BMI through negative affect (\#12). Whereas there was no direct effect of perceived neighborhood disadvantage on BMI, there was a significant indirect effect through social support and through negative affect, as well as an indirect effect including both social support and negative affect: Perceived neighborhood disadvantage was inversely associated with social support, and social support was inversely associated with negative affect. Negative affect was positively associated with BMI. The estimated coefficient was highest for the pathway from SES through social support to BMI (although overall the direct effect of SES on BMI remained the strongest). A comparable pattern of results was found in a similar study (D1*M4), but the pathways reached only marginal significance (\#11). Similar results were found in a study (D1*M4) examining food insecurity, the insecurity and anxiety associated with accessing adequate food (\#3). The direct effect of SES on BMI remained the strongest, although a significant pathway was found through food insecurity and depression. SES was inversely related to food insecurity, food insecurity with depression, depression with BMI. These results were only found among women. Among men, SES was inversely related to food insecurity but food insecurity was not related to depression nor BMI.

Two studies using stepwise regressions showed that the association between neighborhood deprivation and $\mathrm{BMI} /$ obesity was not attenuated after inclusion of factors related to stress and depression $(\# 4, \# 16)$. One of these studies $(D 2 * M 4)$ did find that psychological resources such as personal control and conscientiousness reduced the association by $20 \%(\# 4)$. Another study (D2*M2) found that childhood SES was inversely related to riskier family environment, riskier family environment was inversely related to psychosocial functioning (as indicated by a composite score of depression, mastery, and low 
positive/high negative social contacts), and psychosocial functioning was inversely related to BMI (\#18). Table 4 provides an overview of the results.

[Insert Table 4 about here]

\section{Conclusion and discussion}

This contribution offers a systematic review of existing publications that examined psychosocial explanations for the SES gradient in BMI. Overall, the findings provide inconclusive evidence due to significant limitations in research designs and mediation testing, the limited amount of studies per psychosocial factor, and the mixed results as a consequence of inconsistent use of types of samples, SES indicators, and measures across studies (see Table C1 in Appendix C in the Supplemental Material with a detailed overview of measures used in each included study). However, a few conclusions may be cautiously drawn.

First, the findings tend to corroborate the theoretical pathways proposed by, among others, Adler and Ostrove (1999). Support for environmental factors was relatively weaker than that found for the collective role of environmental and psychological factors in explaining associations between SES and weight status. The studies that found (partial) mediation of the SES-BMI association by neighborhood factors, were solely studies that used objective indicators of environmental conditions (Bradshaw, Kent, Henderson, \& Setar, 2017 - \#4, Robert \& Reither, 2004 - \#16). Objective environmental factors are more proximal to SES and concern structural constraints in one's environment that can directly lead to weight gain (e.g., lower access to physical activity resources and nutritious food; Carlson \& Frazão, 2014; Estabrooks, Lee, \& Gyurcsik, 2003), whereas environmental perceptions may capture psychological states related to lower SES, influencing weight through factors such as increased stress levels (Burdette \& Hill, 2008 - \#5; Kendzor et al., 2013 - \#12).

Although four out of seven studies (57\%) found support for mediation by social resources, there were also significant pathways through neighborhood perceptions and 
negative affect (Kendzor et al., 2013 - \#12), and through childhood support (Novak, Ahlgren, C., \& Hammarström, 2006 - \#15) which was relatively more important. The inconsistencies in the findings regarding the social environment suggest different functions of, and different importance accorded to social support across genders and ethnicities. For instance, in the U.S., social support related to one's neighborhood was more important for people with Latino ethnicity than for other ethnic groups (Kendzor et al., 2013 - \#12). Moreover, women may use social support as a way to improve their self-esteem and body acceptance (AugustusHorvath \& Tylka, 2011; Bacon, Stern, Van Loan, \& Keim, 2005; Puhl \& Heur, 2009) whereas for men, social resources may be protective in an indirect manner, for instance, when engaging in exercise during social activities (Novak et al., 2006 - \#15).

Second, the findings indicate a substantial role of psychological factors (unrelated to stress) in the association between SES and BMI. It is important, however, to note that some of these factors were measured with several measures of which only some mediated (part of) the SES-BMI link (e.g., see the results regarding eating motivation/control). Moreover, there is a lack of consistency among the measures used to assess psychological factors. More specifically, whereas the measured factors related to stress (encompassing perceived stress, negative affect, depression) can be considered a generally unified construct, there is a lot of variance in the other psychological factors assessed. Too few studies examined each factor for drawing generalizable conclusions. For instance, a study examining the influence of time perspective found no significant association with obesity (Guthrie et al., 2009 - \#9). Comparisons with similar studies that did find associations between SES and time perspective, or time perspective and BMI (e.g., Adams \& White, 2009; Barlow, Reeves, McKee, Galea, \& Stuckler, 2016), suggests that results vary depending on the age composition of the samples and the scales used to assess time perspective (Crockett, Weinman, Hankins, \& Marteau, 2009). 
Contrary to theories proposing perceived control as a central predictor of health behaviors and weight status (e.g., Bandura, 2004), perceptions of control or self-esteem did not play a key role in the studies included in this review. Similarly, control over eating did not contribute to explaining the association between SES and BMI. The findings related to eating motivation and control suggest that dietary interventions for low-SES individuals should focus on changing eating motivations rather than boosting self-control regarding eating (Dykes, Brunner, Martikainen, \& Wardle, 2004 - \#7; Baughman et al., 2003 - \#1). Possibly this could overcome food intake regardless of one's level of satiation or hunger which has been associated with lower SES (Hill, Prokosch, DelPriore, Griskevicius, \& Kramer, 2016).

Third, support was slightly higher for the pathway through both environmental and psychological factors (pathway C) than the other pathways. A large amount of the studies examining pathway $\mathrm{C}$ used longitudinal designs and SEM models comparing different mediating pathways. Although support was found for the influence of environmental and psychological constraints and resources in the SES-BMI link, SES itself often remained the most significant predictor (e.g., Kendzor et al., 2013 - \#12; Beydoun \& Wang, 2010; \#3). For instance, the study with the highest level of design and analysis, tested a final model including all variables. This model explained $59.5 \%$ of this association between subjective SES and BMI. Childhood and adult SES and environmental factors explained $48.6 \%$ while psychological and health factors explained an additional $10.9 \%$.

Lastly, although psychological stress is often proposed as an explanation in the association between SES and BMI, less than half of the studies testing stress as a mediator find support for it. This finding is consistent with the inconsistencies found in studies examining the influence of emotions on eating behavior and weight (Ball, Schoenaker, Mishra, 2017; Bongers, de Graaff, \& Jansen, 2016; Dallman, 2010). Gender differences are a 
possible explanation for these inconsistent findings. For instance, Beydoun and Wang (2010 \#3) found that men with depression were less likely to be overweight or morbidly obese, whereas women with depression were three times more likely to be morbidly obese. Yang, Matthews, and Chen (2014 - \#22) found a positive relationship between stress and BMI for both genders but the difference in BMI between low and highly stressed participants was 1.5 times larger among women. Men may have different coping mechanisms for dealing with negative emotions (McRae, Ochsner, Mauss, Gabrieli, \& Gross, 2008), or, alternatively, may report and experience less negative emotions due to lower awareness of their internal bodily sensations (Gersten, 2008).

Furthermore, gender differences in acute and chronic experiences of stress may be another reason for the inconsistent findings (Torres \& Nowson, 2007). For instance, Wickrama, O’Neal, and Oshri (2014a - \#21) found that accumulation of adverse childhood experiences was positively related to BMI later in life among women, but not among men, which is consistent with other research findings (Chapman, 2009 - \#6; Solís et al., 2015). Likewise, Hill, Rodeheffer, DelPriore, and Butterfield (2013) showed that environmental harshness in childhood as well as experimentally manipulated harshness cues were related to increased caloric intake and less weight concern for women. Increased vulnerability to chronic stressors may offer an explanation for why the SES-BMI link is more consistently found among women than among men and for the finding that more support is found for stress as a mediator in the SES-BMI association for women than for men (e.g., Gebreab et al., 2012 - \#8). Accumulation of stressful experiences related to SES adapts psychological responses to stressful triggers and can cause neurobiological changes in appetite and motivation, leading to unhealthier eating patterns and propensity to weight gain (Adam \& Epel, 2007; Dallman et al., 2003; Yau \& Potenza, 2013).

\section{Limitations and Suggestions for Future Research}


One of the limitations is the relatively small amount of articles examining mediational pathways linking SES and BMI. In our selection of articles, we only included studies using designs that could establish causal inference. Methodological soundness was deemed more important for the objective of this review than widening the inclusion parameters to include more articles. However, it is possible that some important factors are absent in this overview. For instance, none of the included articles examined factors related to stigmatization of low SES individuals, or to weight-related stigma (McLaren, 2007). Moreover, a recent paper suggests that cultural influences and the symbolic value of foods should also be considered when explaining social gradients in diets. Fielding-Singh (2017) showed that the meaning parents attach to food, and the way in which these meanings affect the food they purchase for their children, differs across SES level.

One approach for increasing the number of articles found would be to include search terms related to specific psychosocial mediators such as 'stress' (for an example, see Matthews and colleagues, 2010). We specifically did not choose this approach because we believed this would bias the article search towards findings consistent with our individual preconceptions about pathways underlying the SES-BMI link. We chose to search for keywords related to the main key concepts according to proposed methodologies for systematic reviews (e.g., Mertens, 2014). This search already led to a large number of articles. Nonetheless, future work could certainly provide a focused exploration of the role of specific factors in the link between SES and BMI.

Another limitation of the relatively small selection of studies is that more systematic research is warranted examining the influence of various combinations of SES and psychosocial indicators, to reveal potential distinctive associations. For instance, the association between employment and BMI may be explained by perceived job control, whereas that of income and BMI may not (Sobal, 1991). Moreover, previous studies suggest 
differences in the relative importance of SES indicators. For instance, low SES in early life may set out a path towards psychosocial characteristics and unhealthy behaviors that is more predictive of illness than low SES in adulthood (Simpson, Griskevicius, Kuo, Sung, \& Collins, 2012; Lynch, Kaplan, \& Salonen, 1997). Scholars also emphasize the importance of distinguishing between the instrumental function of financial resources and relative deprivation (i.e., the subjective experience of dissatisfaction that can lead to feelings of resentment and anger), which can help clarify the processes underlying SES-BMI associations (Bernstein \& Crosby, 1980; Boyce, Brown, \& Moore, 2010; Goudeau, Autin, \& Croizet, 2017). Whereas recent studies suggest that relative income and perceptions of relative deprivation show a greater association with BMI and obesity than absolute or objective measures of income (Daly, Boyce, \& Wood, 2015; Davillas \& Benzeval, 2016), only one study included in this review included it as a measure, showing that lower subjective SES was for more than 50\% associated to BMI and obesity, independent of childhood and adult SES (Bradshaw et al., 2017 - \#4).

A major limitation of the research under examination is the limited use of designs and analyses that allow for strong causal inferences and for quantifying the mediational role of psychosocial factors in the relationship between SES and BMI. Most published studies concerned with psychosocial mediations were cross-sectional. And, among the limited number of longitudinal studies that addressed this pathway, none relied on a cross-lagged design that would have allowed for stronger inferences. Regarding the mediation tests, very few tested for statistical significance of the indirect pathway of interest and many were not principally interested in examining mediation. None of them tested for alternative directions of pathways (which is necessary to establish mediation: Fiedler, Schott, \& Meiser, 2011). The low scores for empirical conclusiveness in nearly all studies made it impossible to conclude on the support for or against mediation by comparing the relative strength of the studies. 
Moreover, the current studies use different measures or questionnaires to assess similar factors, often included in models simultaneously with other factors. Whereas this could provide information about the relative strength of a predictor compared to another, these analyses are often carried out with little theoretical justification. In addition, they often do not allow assessing the relative importance of one factor over another due to simultaneous addition of variables in a model, or due to the use of non-standardized coefficients (e.g., Baughman et al., 2003 - \#1).

Significant empirical advances need to be achieved in order to better address the causal pathways between SES and weight, using study designs that make it possible to infer causality (Burkholder \& Harlow, 2003; Kearney, 2017; Mulatu \& Schooler, 2002). Some studies suggest a bi-directional relationship between SES and weight. For instance, obesity might lower a person's chances of being hired for a job, or increase the risk of discrimination in the health care system, thereby leading to lower SES (Nobles, Weintraub, \& Adler, 2013; Agerström \& Rooth, 2011; Puhl \& Heuer, 2009). Random assignment of participants to different SES conditions would be ideal but, although possible (e.g., Sim, Lim, Leow, \& Cheon, 2017; Spears, 2011), is problematic for practical and ethical reasons. Manipulating a psychosocial mediator is a reasonable method but is hard to carry out in a field study. As an additional issue, mediation has to be demonstrated in the first place, before conceptually intervening on a mediational factor. As we have seen, evidence for mediation is only suggestive at this stage. Nevertheless, effect size of a mediator and pragmatic value do not necessarily overlap (i.e. less powerful mediators may be easier to intervene on, for ethical, or practical reasons). An alternative method would be to manipulate perceptions of, for instance, subjective status or psychological stress, and examine the influence on health behaviors rather than on weight change. For instance, using this approach, Bratanova, Loughnan, Klein, 
Claassen, and Wood (2016) showed that social anxiety mediated associations between lower SES (both self-reported and manipulated) and caloric intake.

The lack of intervention or trial studies in the adult population is unfortunate given the practical limitations of experimental designs to test changes in BMI as a function of status differences. We found one intervention study in an adult, low-income sample in Brazil. This study consisted of workshops aimed at improving autonomous decision-making and overcoming barriers related to desired dietary change. The intervention led to a significant amount of weight loss during the 6-month intervention (a reduction in BMI of $-0.44 \pm 1.06$; de Menezes, Mingoti, Cardoso, de Deus Mendonça, \& Lopes, 2015). No significant weight loss occurred in participants in the control condition, who participated in exercise and nutrition education sessions, which were also followed by the participants in the intervention group. Although all participants were of low family income $(<\$ 292$ per capita), and cost was not a focus in the intervention, income was one of the factors associated with weight loss in the intervention group, besides dietary change. Future work should keep into consideration that even within SES groups, and especially so among lower SES ones, there is large variability. Given the fact that SES remained a significant predictor alongside psychosocial factors in many of the studies examined, it is important to examine variability even within specific SES groups.

Another limitation of the literature is the focus on BMI as the sole indicator of weight status, specifically in the context of gender and ethnic differences. On average, men tended to be heavier than women when comparing BMIs (Matheson et al., 2008; - \#14; Novak et al., 2006 - \#15), but more women were classified as (morbidly) obese (Beydoun \& Wang, 2010 \#3; Baughman et al., 2003 - \#1). Men have a heavier muscle and bone mass and a higher density of fat free body mass than women (Gallagher et al., 1996), yet the same BMI cut-off values are used to classify men and women into obesity classes. The same problem holds for 
ethnic differences in body types and fat distribution (Deurenberg, Yap, \& Van Staveren, 1998). This may lead to misrepresentation of findings. We recommend future studies to measure weight rather than relying on self-reported weight, and to include several indicators such as BMI, waist circumference, or percent body fat (Davillas \& Benzeval, 2016; Tomiyama, Hunger, Nguyen-Cuu, \& Wells, 2016). Some of the studies discussed in this review used alternative obesity-indicators alongside BMI and found distinct results depending on the measure examined. For instance, Schulz and colleagues (2008 - \#17) found no influence of income on BMI in an ethnically diverse sample, but did find that lower income was related to higher waist circumference (which had different cut-off values for men and women) and that this relationship was mediated by stressful life events.

\section{Theoretical and Policy Implications}

Based on the findings of this systematic review, several suggestions can be formulated for future interventions and policies. First of all, the findings tend to provide support for the theoretical models proposed by authors such as Adler and Ostrove (1999). SES is associated with BMI through environmental and psychological factors individually, but support is also found for a pathway through which environmental factors influence psychological processes that affect weight status. This highlights the importance of taking into consideration (social) environmental and contextual situations alongside SES factors when targeting health interventions to specific groups or people (Chen \& Paterson, 2006).

Nevertheless, it is striking to see the relatively poor quality of designs and mediation tests of studies examining causal pathways through which SES influences weight status. Without convincing evidence about which specific psychosocial factor(s) mediate(s) the relationship between SES and BMI, it is not possible to create effective interventions targeting a factor that might play a role in the relationship. It is critical to establish which factors translate lower SES into increased weight. All intervention studies that we found were 
carried out among children, adolescent populations, or only among lower SES people. In order to determine how to reduce socioeconomic inequalities, interventions should be carried out in broader populations as well.

The direct effect of SES on obesity remained statistically significant in many of the studies, indicating the importance of also addressing the structural antecedents of obesity (Link \& Phelan, 1999). The same applies for factors regarding the physical and social environment which explained part of the association between low SES and BMI. Thus, besides targeting health interventions to individuals themselves, structural interventions or policy-changes such as environmental modifications, or food procurement policies need to be considered (Turrell \& Vandevijvere, 2015).

Important to keep in mind are possible discrepancies between objectively measured economic or social constraints and subjective experiences of these constraints (Powell-Wiley et al., 2014). For instance, diminishing the amount of crime rates in a neighborhood may not lead to changes in the perception of the amount of crime rates in one's neighborhood. Moreover, a gap between one's level of personal wealth and the average wealth of people in one's neighborhood can have detrimental psychological and behavioral consequences due to upward comparisons to a possibly unattainable higher standard (Roy, Godfrey, \& Rarick, 2016; Sanchez-Vaznaugh, Kawachi, Subramanian, Sanchez, \& Acevdeo-Garcia, 2009). Structural changes should be accompanied by subjective evaluations provided by the targeted population.

Improving the conditions of physical and social environments can help decrease weight gains, or diminish weight increases among low SES individuals, through an indirect influence on more positive emotions and lowered stress experiences. Besides changing structural and environmental factors, lower SES people could also benefit from individually tailored interventions. These could, for instance, focus on improving self-esteem or changing 
eating motivations towards healthier types of food (Lasikiewicz, Myrissa, Hoyland, \& Lawton, 2014).

The differences found among genders and ethnic groups, although not the focus in this paper, highlight the importance of considering cultural differences in perceptions of healthiness and body satisfaction, as well as addressing societal issues such as gendered weight norms. Future studies should focus on examining subgroups of low and high SES more closely, taking into account cultural and ideological differences regarding material goods and status as well as beliefs and values about food (Sobal, 1991; Wang, Worsley, \& Cunningham, 2008). In particular, clarifying such racial/ethnic differences could help refine SES-BMI pathways in men, which vary among racial or ethnic subgroups (Ogden, Lamb, Carroll, \& Flegal, 2010; Godley \& McLaren, 2010).

The present review illustrates the possible role of psychological factors in translating lower SES and environmental and social deprivation into higher BMI. Although the statistically explained variances are small and both designs and statistical approaches are problematic, the preliminary findings suggest potentially relevant mechanisms explaining the relation between SES and weight status. The existing literature examining psychosocial explanations of the SES-BMI relationship point to promising findings that bring us closer to understanding the intricate workings of socioeconomic influences on psychologically different individuals in social environments. 


\section{References}

Adam, T. C., \& Epel, E. S. (2007). Stress, eating and the reward system. Physiology \& Behavior, 91(4), 449-458. https://doi.org/10.1016/j.physbeh.2007.04.011.

Adams, J., \& White, M. (2009). Time perspective in socioeconomic inequalities in smoking and body mass index. Health Psychology, 28(1), 83-90. http://dx.doi.org/10.1037/0278-6133.28.1.83.

Adler, N. E., \& Ostrove, J. M. (1999). Socioeconomic status and health: what we know and what we don't. Annals of the New York academy of Sciences, 896(1), 3-15. https://doi.org/10.1111/j.1749-6632.1999.tb08101.x.

Adler, N. E., \& Snibbe, A. C. (2003). The role of psychosocial processes in explaining the gradient between socioeconomic status and health. Current Directions in Psychological Science, 12(4), 119-123. https://doi.org/10.1111/1467-8721.01245.

Agerström, J., \& Rooth, D. O. (2011). The role of automatic obesity stereotypes in real hiring discrimination. Journal of Applied Psychology, 96(4), 790-805. https://doi.org/10.1037/a0021594.

Aggarwal, A., Monsivais, P., Cook, A. J., \& Drewnowski, A. (2011). Does diet cost mediate the relation between socioeconomic position and diet quality? European Journal of Clinical Nutrition, 65(9), 1059-1066. https://doi.org/10.1038/ejcn.2011.72.

Augustus-Horvath, C. L., \& Tylka, T. L. (2011). The acceptance model of intuitive eating: a comparison of women in emerging adulthood, early adulthood, and middle adulthood. Journal of Counseling Psychology, 58(1), 110-125. https://doi.org/10.1037/a0022129.

Bacon, L., Stern, J. S., Van Loan, M. D., \& Keim, N. L. (2005). Size acceptance and intuitive eating improve health for obese, female chronic dieters. Journal of the 
American Dietetic Association, 105(6), 929-936.

https://doi.org/10.1016/i.jada.2005.03.011.

Bandura, A. (2004). Health promotion by social cognitive means. Health education \& behavior, 31(2), 143-164. https://doi.org/10.1177/1090198104263660.

Ball, K., Schoenaker, D. A., \& Mishra, G. D. (2017). Does psychosocial stress explain socioeconomic inequities in 9-year weight gain among young women? Obesity, 25(6), 1109-1114. https://doi.org/10.1002/oby.21830.

*Baughman, K., Logue, E., Sutton, K., Capers, C., Jarjoura, D., \& Smucker, W. (2003). Biopsychosocial characteristics of overweight and obese primary care patients: do psychosocial and behavior factors mediate sociodemographic effects? Preventive Medicine, 37(2), 129-137. https://doi.org/10.1016/S0091-7435(03)00095-1.

Baum, A., Garofalo, J. P., \& Yali, A. N. N. (1999). Socioeconomic status and chronic stress: does stress account for SES effects on health? Annals of the New York Academy of Sciences, 896(1), 131-144. https://doi.org/10.1111/j.1749-6632.1999.tb08111.x.

Barlow, P., Reeves, A., McKee, M., Galea, G., \& Stuckler, D. (2016). Unhealthy diets, obesity and time discounting: a systematic literature review and network analysis. Obesity Reviews, 17(9), 810-819. https://doi.org/10.1111/obr.12431.

Baron, R. M., \& Kenny, D. A. (1986). The moderator-mediator variable distinction in social psychological research: Conceptual, strategic, and statistical considerations. Journal of personality and social psychology, 51(6), 1173-1182. https://doi.org/10.1037/00223514.51.6.1173.

Barrick, M. R., \& Mount, M. K. (1991). The big five personality dimensions and job performance: a meta-analysis. Personnel psychology, 44(1), 1-26. http://dx.doi.org/10.1111/j.1744-6570.1991.tb00688.x. 
*Bean, C. G., Winefield, H. R., Sargent, C., \& Hutchinson, A. D. (2015). Differential associations of job control components with both waist circumference and body mass index. Social Science \& Medicine, 143, 1-8. http://dx.doi.org/10.1016/j.socscimed.2015.08.034.

Bernstein, M., \& Crosby, F. (1980). An empirical examination of relative deprivation theory. Journal of Experimental Social Psychology, 16(5), 442-456. https://doi.org/10.1016/0022-1031(80)90050-5.

*Beydoun, M. A., \& Wang, Y. (2010). Pathways linking socioeconomic status to obesity through depression and lifestyle factors among young US adults. Journal of Affective Disorders, 123(1), 52-63. https://doi.org/10.1016/j.jad.2009.09.021.

Black, J. L., \& Macinko, J. (2008). Neighborhoods and obesity. Nutrition Reviews, 66(1), 220. https://doi.org/10.1111/j.1753-4887.2007.00001.x.

Bongers, P., de Graaff, A., \& Jansen, A. (2016). 'Emotional' does not even start to cover it: Generalization of overeating in emotional eaters. Appetite, 96, 611-616. http://dx.doi.org/10.1016/j.appet.2015.11.004.

Boyce, C. J., Brown, G. D., \& Moore, S. C. (2010). Money and happiness: Rank of income, not income, affects life satisfaction. Psychological Science, 21(4), 471-475. https://doi.org/10.1177/0956797610362671.

*Bradshaw, M., Kent, B. V., Henderson, W. M., \& Setar, A. C. (2017). Subjective social status, life course SES, and BMI in young adulthood. Health Psychology, 36(7), 682694. http://dx.doi.org/10.1037/hea0000487.

Bratanova, B., Loughnan, S., Klein, O., Claassen, A., \& Wood, R. (2016). Poverty, inequality, and increased consumption of high calorie food: Experimental evidence for a causal link. Appetite, 100, 162-171. https://doi.org/10.1016/j.appet.2016.01.028. 
*Burdette, A. M., \& Hill, T. D. (2008). An examination of processes linking perceived neighborhood disorder and obesity. Social Science \& Medicine, 67(1), 38-46. https://doi.org/10.1016/j.socscimed.2008.03.029.

Bullock, J. G., Green, D. P., \& Ha, S. E. (2010). Yes, but what's the mechanism? (Don't expect an easy answer). Journal of Personality and Social Psychology, 98(4), 550558. http://dx.doi.org/10.1037/a0018933.

Burkholder, G. J., \& Harlow, L. L. (2003). An illustration of a longitudinal cross-lagged design for larger structural equation models. Structural Equation Modeling, 10(3), 465-486. https://doi.org/10.1207/S15328007SEM1003_8.

Capacci, S., Mazzocchi, M., Shankar, B., Brambila Macias, J., Verbeke, W., Pérez-Cueto, F. J., ... \& Saba, A. (2012). Policies to promote healthy eating in Europe: a structured review of policies and their effectiveness. Nutrition Reviews, 70(3), 188-200. https://doi.org/10.1111/j.1753-4887.2011.00442.x.

Carlson, A., \& Frazão, E. (2014). Food costs, diet quality and energy balance in the United States. Physiology \& Behavior, 134, 20-31. http://dx.doi.org/10.1016/j.physbeh.2014.03.001.

*Chapman, B. P. (2009). Can the influence of childhood SES on men and women's adult body mass be explained by adult SES or personality? Findings from a national sample. Health Psychology, 28(4), 419-427. https://doi.org/10.1037/a0015212.

Chen, E., \& Paterson, L. Q. (2006). Neighborhood, family, and subjective socioeconomic status: How do they relate to adolescent health? Health Psychology, 25(6), 704-714. https://doi.org/10.1037/0278-6133.25.6.704.

Cheon, B. K., \& Hong, Y. Y. (2017). Mere experience of low subjective socioeconomic status stimulates appetite and food intake. Proceedings of the National Academy of Sciences, 114(1), 72-77. https://doi.org/10.1073/pnas.1607330114. 
Cohen, J., \& Cohen, P. (1983). Applied multiple regression/correlation analysis for the behavioural sciences. Erlbaum: Hillsdale, N.J.

Cole, D. A., \& Maxwell, S. E. (2003). Testing mediational models with longitudinal data: questions and tips in the use of structural equation modeling. Journal of Abnormal Psychology, 112(4), 558-577. https://doi.org/10.1037/0021-843X.112.4.558.

Crockett, R. A., Weinman, J., Hankins, M., \& Marteau, T. (2009). Time orientation and health-related behaviour: Measurement in general population samples. Psychology and Health, 24(3), 333-350. https://doi.org/10.1080/08870440701813030.

Cummins, S., \& Macintyre, S. (2006). Food environments and obesity-neighborhood or nation? International Journal of Epidemiology, 35(1), 100-104. https://doi.org/10.1093/ije/dyi276.

Dallman, M. F., Pecoraro, N., Akana, S. F., La Fleur, S. E., Gomez, F., Houshyar, H., ... \& Manalo, S. (2003). Chronic stress and obesity: a new view of "comfort food". Proceedings of the National Academy of Sciences, 100(20), 11696-11701. https://doi.org/10.1073/pnas.1934666100.

Dallman, M. F. (2010). Stress-induced obesity and the emotional nervous system. Trends in Endocrinology \& Metabolism, 21(3), 159-165. https://doi.org/10.1016/j.tem.2009.10.004.

Daly, M., Boyce, C., \& Wood, A. (2015). A social rank explanation of how money influences health. Health Psychology, 34(3), 222-230. http://dx.doi.org/10.1037/hea0000098.

Dassen, F. C., Houben, K., \& Jansen, A. (2015). Time orientation and eating behavior: Unhealthy eaters consider immediate consequences, while healthy eaters focus on future health. Appetite, 91, 13-19. https://doi.org/10.1016/j.appet.2015.03.020. 
Daugherty, J. R., \& Brase, G. L. (2010). Taking time to be healthy: Predicting health behaviors with delay discounting and time perspective. Personality and Individual Differences, 48(2), 202-207. https://doi.org/10.1016/j.paid.2009.10.007.

Davillas, A., \& Benzeval, M. (2016). Alternative measures to BMI: Exploring income-related inequalities in adiposity in Great Britain. Social Science \& Medicine, 166, 223-232. http://dx.doi.org/10.1016/j.socscimed.2016.08.032.

Deurenberg, P., Yap, M., \& Van Staveren, W. A. (1998). Body mass index and percent body fat: a meta analysis among different ethnic groups. International Journal of Obesity \& Related Metabolic Disorders, 22(12), 1164-1171. https://doi.org/10.1038/sj.ijo.0800741.

Dinsa, G. D., Goryakin, Y., Fumagalli, E., \& Suhrcke, M. (2012). Obesity and socioeconomic status in developing countries: a systematic review. Obesity Reviews, 13(11), 10671079. https://doi.org/10.1111/j.1467-789X.2012.01017.x.

*Dykes, J., Brunner, E. J., Martikainen, P. T., \& Wardle, J. (2004). Socioeconomic gradient in body size and obesity among women: the role of dietary restraint, disinhibition and hunger in the Whitehall II study. International journal of obesity, 28(2), 262-268. https://doi.org/10.1038/sj.ijo.0802523.

Estabrooks, P. A., Lee, R. E., \& Gyurcsik, N. C. (2003). Resources for physical activity participation: does availability and accessibility differ by neighborhood socioeconomic status? Annals of Behavioral Medicine, 25(2), 100104. https://doi.org/10.1207/s15324796abm2502 05.

Eurostat (2014). Obesity rate by body mass index (BMI). Retrieved from: $\underline{\text { http://ec.europa.eu/eurostat/web/products-datasets/-/sdg } 02 \quad 10}$ 
Fiedler, K., Schott, M., \& Meiser, T. (2011). What mediation analysis can (not) do. Journal of Experimental Social Psychology, 47(6), 1231-1236. https://doi.org/10.1016/j.jesp.2011.05.007.

Fielding-Singh, P. (2017). A Taste of Inequality: Food's Symbolic Value across the Socioeconomic Spectrum. Sociological Science, 4, 424-448. https://doi.org/10.15195/v4.a17.

Fieulaine, N. \& Apostolidis, T. (2015). Precariousness as a Time Horizon: How Poverty and Social Insecurity Shape Individuals’ Time Perspectives. In M. Stolarski, N. Fieulaine, \& W. van Beek (Eds.), Time Perspective Theory; Review, Research and Application (pp. 213-228). Cham: Springer International.

Fikkan, J. L., \& Rothblum, E. D. (2012). Is fat a feminist issue? Exploring the gendered nature of weight bias. Sex Roles, 66, 575-592. https://doi.org/10.1007/s11199-0110022-5.

Fleischhacker, S. E., Evenson, K. R., Rodriguez, D. A., \& Ammerman, A. S. (2011). A systematic review of fast food access studies. Obesity Reviews, 12(5), e460-e471. https://doi.org/10.1111/j.1467-789X.2010.00715.x.

Gallagher, D., Visser, M., Sepulveda, D., Pierson, R. N., Harris, T., \& Heymsfield, S. B. (1996). How useful is body mass index for comparison of body fatness across age, sex, and ethnic groups? American Journal of Epidemiology, 143(3), 228-239. https://doi.org/10.1093/oxfordjournals.aje.a008733.

Gallo, L. C., \& Matthews, K. A. (2003). Understanding the association between socioeconomic status and physical health: do negative emotions play a role? Psychological Bulletin, 129(1), 10-51. https://doi.org/10.1037/00332909.129.1.10. 
*Gebreab, S. Y., Diez-Roux, A. V., Hickson, D. A., Boykin, S., Sims, M., Sarpong, D. F., ... \& Wyatt, S. B. (2012). The contribution of stress to the social patterning of clinical and subclinical CVD risk factors in African Americans: the Jackson Heart Study. Social Science \& Medicine, 75(9), 1697-1707. http://dx.doi.org/10.1016/j.socscimed.2012.06.003.

Gersten, O. (2008). Neuroendocrine biomarkers, social relations, and the cumulative costs of stress in Taiwan. Social Science \& Medicine, 66(3), 507-519. https://doi.org/10.1016/j.socscimed.2007.09.004.

Godley, J., \& McLaren, L. (2010). Socioeconomic status and body mass index in Canada: exploring measures and mechanisms. Canadian Review of Sociology/Revue Canadienne de Sociologie, 47(4), 381-403. https://doi.org/10.1111/j.1755$\underline{618 X .2010 .01244 . X}$.

Goudeau, S., Autin, F., \& Croizet, J. C. (2017). Etudier, Mesurer et Manipuler la Classe Sociale en Psychologie Sociale: Approches Economiques, Symboliques et Culturelles [Studying, Measuring and Manipulating Social Class in Social Psychology: Economic, Symbolic and Cultural Approaches]. International Review of Social Psychology, 30(1), 1-9. https://doi.org/10.5334/irsp.52.

*Guthrie, L. C., Lessl, K., Ochi, O., \& Ward, M. M. (2013). Time perspective and smoking, obesity, and exercise in a community sample. American Journal of Health Behavior, 37(2), 171-180. https://doi.org/10.5993/AJHB.37.2.4.

*Hagger-Johnson, G., Mõttus, R., Craig, L. C., Starr, J. M., \& Deary, I. J. (2012). Pathways from childhood intelligence and socioeconomic status to late-life cardiovascular disease risk. Health Psychology, 31(4), 403-412. https://doi.org/10.1037/a0026775.

Hill, S. E., Prokosch, M. L., DelPriore, D. J., Griskevicius, V., \& Kramer, A. (2016). Low childhood socioeconomic status promotes eating in the absence of energy 
need. Psychological Science, 27(3), 354-364. https://doi.org/10.1177/0956797615621901.

Hill, S. E., Rodeheffer, C. D., DelPriore, D. J., \& Butterfield, M. E. (2013). Ecological contingencies in women's calorie regulation psychology: A life history approach. Journal of Experimental Social Psychology, 49(5), 888-897. https://doi.org/10.1016/j.jesp.2013.03.016.

*Kendzor, D. E., Businelle, M. S., Mazas, C. A., Cofta-Woerpel, L. M., Reitzel, L. R., Vidrine, J. I., ... \& Wetter, D. W. (2009). Pathways between socioeconomic status and modifiable risk factors among African American smokers. Journal of Behavioral Medicine, 32(6), 545-557. https://doi.org/10.1007/s10865-009-9226-3.

*Kendzor, D. E., Businelle, M. S., Cofta-Woerpel, L. M., Reitzel, L. R., Castro, Y., Vidrine, J. I., ... \& Wetter, D. W. (2013). Mechanisms linking socioeconomic disadvantage and BMI in smokers. American Journal of Health Behavior, 37(5), 587-598. https://doi.org/10.5993/AJHB.37.5.2.

*Lacey, R. E., Kumari, M., \& McMunn, A. (2013). Parental separation in childhood and adult inflammation: the importance of material and psychosocial pathways. Psychoneuroendocrinology, 38(11), 2476-2484. http://dx.doi.org/10.1016/j.psyneuen.2013.05.007.

Lasikiewicz, N., Myrissa, K., Hoyland, A., \& Lawton, C. L. (2014). Psychological benefits of weight loss following behavioural and/or dietary weight loss interventions. A systematic research review. Appetite, 72, 123-137. https://doi.org/10.1016/j.appet.2013.09.017.

Link, B. G., \& Phelan, J. (1995). Social conditions as fundamental causes of disease. Journal of Health and Social Behavior, 35, 80-94. https://doi.org/10.2307/2626958. 
Lynch, J. W., Kaplan, G. A., \& Salonen, J. T. (1997). Why do poor people behave poorly? Variation in adult health behaviors and psychosocial characteristics by stages of the socioeconomic life course. Social Science \& Medicine, 44(6), 809-819. https://doi.org/10.1016/S0277-9536(96)00191-8.

Martikainen, P., Bartley, M., \& Lahelma, E. (2002). Psychosocial determinants of health in social epidemiology. International Journal of Epidemiology, 31, 1091-1093. https://doi.org/10.1093/ije/31.6.1091.

MacKinnon, D. P., Krull, J. L., \& Lockwood, C. M. (2000). Equivalence of the mediation, confounding and suppression effect. Prevention Science, 1(4), 173-181. https://doi.org/10.1023/A:1026595011371.

MacKinnon, D. P., Lockwood, C. M., Hoffman, J. M., West, S. G., \& Sheets, V. (2002). A comparison of methods to test mediation and other intervening variable effects. Psychological Methods, 7, 83-104. http://dx.doi.org/10.1037/1082989X.7.1.83.

MacKinnon, D. P., Lockwood, C. M., \& Williams, J. (2004). Confidence limits for the indirect effect: Distribution of the product and resampling methods. Multivariate behavioral research, 39(1), 99-128. https://doi.org/10.1207/s15327906mbr3901 4.

*Matheson, F. I., Moineddin, R., \& Glazier, R. H. (2008). The weight of place: a multilevel analysis of gender, neighborhood material deprivation, and body mass index among Canadian adults. Social Science \& Medicine, 66(3), 675-690. https://doi.org/10.1016/j.socscimed.2007.10.008.

Matthews, K. A., Gallo, L. C., \& Taylor, S. E. (2010). Are psychosocial factors mediators of socioeconomic status and health connections? Annals of the New York Academy of Sciences, 1186(1), 146-173. https://doi.org/10.1111/j.1749-6632.2009.05332.x. 
McFadden, A., Green, J. M., Williams, V., McLeish, J., McCormick, F., Fox-Rushby, J., \& Renfrew, M. J. (2014). Can food vouchers improve nutrition and reduce health inequalities in low-income mothers and young children: A multi-method evaluation of the experiences of beneficiaries and practitioners of the Healthy Start programme in England. BMC Public Health, 14(1), 148. https://doi.org/10.1186/1471-2458-14-148.

McLaren, L. (2007). Socioeconomic status and obesity. Epidemiologic Reviews, 29(1), 29-48. https://doi.org/10.1093/epirev/mxm001.

McRae, K., Ochsner, K. N., Mauss, I. B., Gabrieli, J. J., \& Gross, J. J. (2008). Gender differences in emotion regulation: An fMRI study of cognitive reappraisal. Group processes \& intergroup relations, 11(2), 143-162.

https://doi.org/10.1177/1368430207088035.

Mejia, N., Lightstone, A. S., Basurto-Davila, R., Morales, D. M., \& Sturm, R. (2015). Peer Reviewed: Neighborhood Food Environment, Diet, and Obesity Among Los Angeles County Adults, 2011. Preventing Chronic Disease, 12, E143. https://doi.org/10.5888/pcd12.150078.

de Menezes, M. C., Mingoti, S. A., Cardoso, C. S., de Deus Mendonça, R., \& Lopes, A. C. S. (2015). Intervention based on Transtheoretical Model promotes anthropometric and nutritional improvements-A randomized controlled trial. Eating Behaviors, 17, 37 44. https://doi.org/10.1016/j.eatbeh.2014.12.007.

Mertens, D. M. (2014). Research and evaluation in education and psychology: Integrating diversity with quantitative, qualitative, and mixed methods. Sage publications.

Moher D, Liberati A, Tetzlaff J, Altman DG, The PRISMA Group (2009). Preferred Reporting Items for Systematic Reviews and Meta-Analyses: The PRISMA Statement. PLoS Med 6(7): e1000097. https://doi.org/10.1371/journal.pmed1000097. Mooney, S. J., Baecker, A., \& Rundle, A. G. (2013). Comparison of anthropometric and body 
composition measures as predictors of components of the metabolic syndrome in a clinical setting. Obesity Research \& Clinical Practice, 7(1), e55-e66.

http://dx.doi.org/10.1016/j.orcp.2012.10.004.

Moore, C. J., \& Cunningham, S. A. (2012). Social position, psychological stress, and obesity: a systematic review. Journal of the Academy of Nutrition and Dietetics, 112(4), 518526. https://doi.org/10.1016/j.jand.2011.12.001.

Mulatu, M. S., \& Schooler, C. (2002). Causal connections between socio-economic status and health: reciprocal effects and mediating mechanisms. Journal of Health and Social Behavior, 43(1), 22-41. http://dx.doi.org/10.2307/3090243.

Nettle, D., Andrews, C., \& Bateson, M. (2017). Food insecurity as a driver of obesity in humans: The insurance hypothesis. Behavioral and Brain Sciences, e105, 1-53. https://doi.org/10.1017/S0140525X16000947.

Nobles, J., Weintraub, M. R., \& Adler, N. E. (2013). Subjective socioeconomic status and health: relationships reconsidered. Social Science \& Medicine, 82, 58-66. http://dx.doi.org/10.1016/j.socscimed.2013.01.021.

*Novak, M., Ahlgren, C., \& Hammarström, A. (2006). A life-course approach in explaining social inequity in obesity among young adult men and women. International Journal of Obesity, 30(1), 191-200. https://doi.org/10.1038/sj.ijo.0803104.

Oatley, K., Keltner, D., \& Jenkins, J. M. (2006). Understanding emotions. Blackwell publishing.

OECD (2017). OECD Health Statistics 2017. Retrieved from: http://www.oecd.org/health/health-data.htm

Oexle, N., Barnes, T. L., Blake, C. E., Bell, B. A., \& Liese, A. D. (2015). Neighborhood fast food availability and fast food consumption. Appetite, 92, 227-232. http://dx.doi.org/10.1016/j.appet.2015.05.030. 
Ogden, C.L., Lamb, M.M., Carroll, M.D., \& Flegal, K.M. (2010). Obesity and Socioeconomic Status in Adults: United States, 2005-2008. Retrieved from: https://www.cdc.gov/nchs/products/databriefs/db50.htm

Pampel, F. C., Denney, J. T., \& Krueger, P. M. (2012). Obesity, SES, and economic development: a test of the reversal hypothesis. Social Science \& Medicine, 74(7), 1073-1081. https://doi.org/10.1016/j.socscimed.2011.12.028.

Pickett, K. E., Kelly, S., Brunner, E., Lobstein, T., \& Wilkinson, R. G. (2005). Wider income gaps, wider waistbands? An ecological study of obesity and income inequality. Journal of Epidemiology \& Community Health, 59(8), 670-674. https://doi.org/10.1136/jech.2004.028795.

Powell-Wiley, T. M., Ayers, C., Agyemang, P., Leonard, T., Berrigan, D., Ballard-Barbash, R., ... \& Hoehner, C. M. (2014). Neighborhood-level socioeconomic deprivation predicts weight gain in a multi-ethnic population: longitudinal data from the Dallas Heart Study. Preventive Medicine, 66, 22-27. http://dx.doi.org/10.1016/j.ypmed.2014.05.011.

Powell, L. M., \& Chaloupka, F. J. (2009). Food prices and obesity: evidence and policy implications for taxes and subsidies. The Milbank Quarterly, 87(1), 229-257. https://doi.org/10.1111/j.1468-0009.2009.00554.x.

Preacher, K. J., \& Hayes, A. F. (2008). Asymptotic and resampling strategies for assessing and comparing indirect effects in multiple mediator models. Behavior Research Methods, 40(3), 879-891. https://doi.org/10.3758/BRM.40.3.879.

Primavesi, L., Caccavelli, G., Ciliberto, A., \& Pauze, E. (2015). Nutrieconomic model can facilitate healthy and low-cost food choices. Public Health Nutrition, 18(5), 827-835. https://doi.org/10.1017/S1368980014002651. 
Puhl, R. M., \& Heuer, C. A. (2009). The stigma of obesity: a review and update. Obesity, 17(5), 941-964. Obesity (2009) 17, 941-964. https://doi.org/10.1038/oby.2008.636.

*Robert, S. A., \& Reither, E. N. (2004). A multilevel analysis of race, community disadvantage, and body mass index among adults in the US. Social Science \& Medicine, 59(12), 2421-2434. https://doi.org/10.1016/j.socscimed.2004.03.034.

Robertson, A., Lobstein, T., \& Knai, C. (2007). Obesity and socio-economic groups in Europe: Evidence review and implications for action. Retrieved from: https://www.ucviden.dk/ws/files/14424675/DG_Sanco_SES and_Obesity_29_Nov_0 7.pdf

Rokholm, B., Baker, J. L., \& Sørensen, T. I. A. (2010). The levelling off of the obesity epidemic since the year 1999-a review of evidence and perspectives. Obesity Reviews, 11(12), 835-846. https://doi.org/10.1111/j.1467-789X.2010.00810.x.

Roy, A. L., Godfrey, E. B., \& Rarick, J. R. (2016). Do we know where we stand? Neighborhood relative income, subjective social status, and health. American Journal of Community Psychology, 57(3-4), 448-458. https://doi.org/10.1002/ajcp.12049.

Sánchez-Vaznaugh, E. V., Kawachi, I., Subramanian, S. V., Sánchez, B. N., \& AcevedoGarcia, D. (2009). Do socioeconomic gradients in body mass index vary by race/ethnicity, gender, and birthplace? American Journal of Epidemiology, 169(9), 1102-1112. https://doi.org/10.1002/ijop.12437.

*Schulz, A. J., House, J. S., Israel, B. A., Mentz, G., Dvonch, J. T., Miranda, P. Y., ... \& Koch, M. (2008). Relational pathways between socioeconomic position and cardiovascular risk in a multiethnic urban sample: complexities and their implications for improving health in economically disadvantaged populations. Journal of 
Epidemiology \& Community Health, 62(7), 638-646. https://doi.org/10.1136/jech.2007.063222.

Selig, J. P., \& Preacher, K. J. (2009). Mediation models for longitudinal data in developmental research. Research in Human Development, 6(2-3), 144-164. http://dx.doi.org/10.1080/15427600902911247.

Shrewsbury, V., \& Wardle, J. (2008). Socioeconomic status and adiposity in childhood: a systematic review of cross-sectional studies 1990-2005. Obesity, 16(2), 275-284. https://doi.org/10.1038/oby.2007.35.

Sim, A. Y., Lim, E. X., Forde, C. G., \& Cheon, B. K. (2018). Personal relative deprivation increases self-selected portion sizes and food intake. Appetite, 121, 268-274. https://doi.org/10.1016/j.appet.2017.11.100.

Sim, A. Y., Lim, E. X., Leow, M. K., \& Cheon, B. K. (2018). Low subjective socioeconomic status stimulates orexigenic hormone ghrelin-a randomised trial. Psychoneuroendocrinology, 89, 103-112. https://doi.org/10.1016/j.psyneuen.2018.01.006.

Simpson, J. A., Griskevicius, V., Kuo, S. I., Sung, S., \& Collins, W. A. (2012). Evolution, stress, and sensitive periods: the influence of unpredictability in early versus late childhood on sex and risky behavior. Developmental Psychology, 48(3), 674. https://doi.org/10.1037/a0027293.

Smith, E. R. (1982). Beliefs, attributions, and evaluations: Nonhierarchical models of mediation in social cognition. Journal of Personality and Social Psychology, 43(2), 248-259. https://doi.org/10.1037/0022-3514.43.2.248.

Sobal, J., \& Stunkard, A. J. (1989). Socioeconomic status and obesity: a review of the literature. Psychological Bulletin, 105(2), 260-275. 
Sobal, J. (1991). Obesity and socioeconomic status: a framework for examining relationships between physical and social variables. Medical Anthropology, 13(3), 231-247.

Sobel, M. E. (1982). Asymptotic confidence intervals for indirect effects in structural equation models. Sociological methodology, 13, 290-312. https://doi.org/10.2307/270723.

Solís, C. B., Kelly-Irving, M., Fantin, R., Darnaudéry, M., Torrisani, J., Lang, T., \& Delpierre, C. (2015). Adverse childhood experiences and physiological wear-and-tear in midlife: Findings from the 1958 British birth cohort. Proceedings of the National Academy of Sciences, 112(7), E738-E746. https://doi.org/10.1073/pnas.1417325112.

Spencer, S. J., Zanna, M. P., \& Fong, G. T. (2005). Establishing a causal chain: why experiments are often more effective than mediational analyses in examining psychological processes. Journal of Personality and Social Psychology, 89(6), 845851. https://doi.org/10.1037/0022-3514.89.6.845.

Spears, D. (2011). Economic decision-making in poverty depletes behavioral control. The BE Journal of Economic Analysis \& Policy, 11(1), 1-42. https://doi.org/10.2202/19351682.2973.

Story, M., Kaphingst, K. M., Robinson-O'Brien, R., \& Glanz, K. (2008). Creating healthy food and eating environments: policy and environmental approaches. Annual Review of Public Health, 29, 253-272. https://doi.org/10.1146/annurev.publhealth.29.020907.090926.

Tanumihardjo, S. A., Anderson, C., Kaufer-Horwitz, M., Bode, L., Emenaker, N. J., Haqq, A. M., ... \& Stadler, D. D. (2007). Poverty, obesity, and malnutrition: an international perspective recognizing the paradox. Journal of the Academy of Nutrition and Dietetics, 107(11), 1966-1972. https://doi.org/10.1016/j.jada.2007.08.007. 
*Taylor, S. E., Lehman, B. J., Kiefe, C. I., \& Seeman, T. E. (2006). Relationship of early life stress and psychological functioning to adult C-reactive protein in the coronary artery risk development in young adults study. Biological Psychiatry, 60(8), 819-824. https://doi.org/10.1016/j.biopsych.2006.03.016.

Tomiyama, A. J. (2014). Weight stigma is stressful. A review of evidence for the Cyclic Obesity/Weight-Based Stigma model. Appetite, 82, 8-15. https://doi.org/10.1016/j.appet.2014.06.108.

Tomiyama, A. J., Hunger, J. M., Nguyen-Cuu, J., \& Wells, C. (2016). Misclassification of cardiometabolic health when using body mass index categories in NHANES 20052012. International Journal of Obesity, 40(5), 883-886. https://doi.org/10.1038/ijo.2016.17.

Torres, S. J., \& Nowson, C. A. (2007). Relationship between stress, eating behavior, and obesity. Nutrition, 23(11), 887-894. https://doi.org/10.1016/j.nut.2007.08.008.

Turrell, G., \& Vandevijvere, S. (2015). Socio-economic inequalities in diet and body weight: evidence, causes and intervention options. Public Health Nutrition, 18(5), 759-763. https://doi.org/10.1017/S1368980015000233.

Vartanian, L. R., \& Porter, A. M. (2016). Weight stigma and eating behavior: a review of the literature. Appetite, 102, 3-14. http://dx.doi.org/10.1016/j.appet.2016.01.034.

*Veenstra, G., Luginaah, I., Wakefield, S., Birch, S., Eyles, J., \& Elliott, S. (2005). Who you know, where you live: social capital, neighborhood and health. Social Science \& Medicine, 60(12), 2799-2818. https://doi.org/10.1016/j.socscimed.2004.11.013.

*Wamala, S. P., Wolk, A., \& Orth-Gomér, K. (1997). Determinants of obesity in relation to socioeconomic status among middle-aged Swedish women. Preventive Medicine, 26(5), 734-744. https://doi.org/10.1006/pmed.1997.0199. 
Wang, Y., \& Beydoun, M. A. (2007). The obesity epidemic in the United States—gender, age, socioeconomic, racial/ethnic, and geographic characteristics: a systematic review and meta-regression analysis. Epidemiologic reviews, 29(1), 6-28. https://doi.org/10.1093/epirev/mxm007.

Wang, W. C., Worsley, A., \& Cunningham, E. G. (2008). Social ideological influences on reported food consumption and BMI. International Journal of Behavioral Nutrition and Physical Activity, 5, 20. https://doi.org/10.1186/1479-5868-5-20.

WHO (2017a). Cardiovascular diseases (CVDs). Retrieved from: http://www.who.int/mediacentre/factsheets/fs317/en/

WHO (2017b). Obesity and overweight. Retrieved from: http://www.who.int/mediacentre/factsheets/fs311/en/

*Wickrama, K. K., O’Neal, C. W., \& Oshri, A. (2014). Are stressful developmental processes of youths leading to health problems amplified by genetic polymorphisms? The case of body mass index. Journal of Youth and Adolescence, 43(7), 1096-1109. https://doi.org/10.1007/s10964-014-0109-8.

*Yang, T. C., Matthews, S. A., \& Chen, V. Y. J. (2014). Stochastic variability in stress, sleep duration, and sleep quality across the distribution of body mass index: insights from quantile regression. International Journal of Behavioral Medicine, 21(2), 282-291. https://doi.org/10.1007/s12529-013-9293-2.

Yau, Y. H., \& Potenza, M. N. (2013). Stress and eating behaviors. Minerva Endocrinologica, 38(3), 255-267.

Zhao, X., Lynch Jr, J. G., \& Chen, Q. (2010). Reconsidering Baron and Kenny: Myths and truths about mediation analysis. Journal of consumer research, 37(2), 197-206. https://doi.org/10.1086/651257. 
Clqssification Qfincluded studiess acerrding tQ the empirical conclusiveness of their design and statistical approach to mediation testing. The color of the cell provides an indication of the overall strength of evidence, ranging from best (dark grey cells), to moderate (ight grey cells), to low (plain cells).

\begin{tabular}{|c|c|c|c|c|c|c|}
\hline & & \multicolumn{5}{|c|}{ M1_5: MEDIATION TEST } \\
\hline & & M1 - Coefficient test & $\begin{array}{l}\text { M2 - Causal steps } \\
\text { approach }\end{array}$ & $\begin{array}{l}\text { M3 - Statistical } \\
\text { significance }\end{array}$ & $\begin{array}{l}\text { M4 - Alternative } \\
\text { mediators }\end{array}$ & M5 - Order of variables \\
\hline \multirow{4}{*}{ D1_4: DESIGN } & D1 - Cross-sectional & $\begin{array}{c}\text { Bean (\#2) } \\
\text { Burdette (\#5) } \\
\text { Matheson (\#14) } \\
\text { Robert (\#16) } \\
\text { Veenstra (\#19) } \\
\text { Yang (\#22) }\end{array}$ & $\begin{array}{c}\text { Baughman (\#1) } \\
\text { Dykes (\#7) } \\
\text { Guthrie (\#9) } \\
\text { Schulz (\#17) } \\
\text { Wamala (\#20) }\end{array}$ & Gebreab (\#8) & $\begin{array}{c}\text { Beydoun (\#3) } \\
\text { Kendzor (2009; \#11) } \\
\text { Kendzor (2013; \#12) }\end{array}$ & \\
\hline & D2 - Longitudinal & $\begin{array}{l}\text { Chapman (\#6) } \\
\text { Novak (\#15) }\end{array}$ & $\begin{array}{c}\text { Hagger-Johnson (\#10) } \\
\text { Lacey (\#13) } \\
\text { Taylor (\#18) } \\
\text { Wickrama (\#21) }\end{array}$ & & Bradshaw (\#4) & \\
\hline & D3 - Cross-lagged & & & & & \\
\hline & D4 - Experimental & & & & & \\
\hline
\end{tabular}


Table 2.

Studies examining environmental constraints and resources as a mediating pathway between SES and BMI (pathway A).

\begin{tabular}{|c|c|c|c|c|c|c|c|c|c|c|c|}
\hline \multirow[t]{3}{*}{ Study } & \multicolumn{6}{|c|}{ SES indicator } & \multicolumn{5}{|c|}{ Environmental factor } \\
\hline & \multirow[b]{2}{*}{ Income } & \multirow[b]{2}{*}{ Education } & \multirow[b]{2}{*}{ Employment } & \multirow[b]{2}{*}{ Composite } & \multirow[b]{2}{*}{ Childhood } & \multirow[b]{2}{*}{ Subjective } & \multicolumn{4}{|c|}{ Physical } & \multirow{2}{*}{$\frac{\text { Social }}{\text { Social resource }}$} \\
\hline & & & & & & & $\begin{array}{l}\text { Neighborhood } \\
\text { disadvantage }\end{array}$ & $\begin{array}{c}\text { Food } \\
\text { insecurity }\end{array}$ & Job stress & $\begin{array}{c}\text { Stress/low } \\
\text { control at home } \\
\text { and school }\end{array}$ & \\
\hline$\# 1$ & & $\cdot$ & $\cdot$ & & & & & & & & $\boldsymbol{J / X ( \mathrm { D } 1 * \mathrm { M } 2 )}$ \\
\hline$\# 2$ & • & & $\cdot$ & & & & & & $x(\mathrm{D} 1 * \mathrm{M} 1)$ & & \\
\hline$\# 3$ & & & & $\cdot$ & & & & $x(\mathrm{D} 1 * \mathrm{M} 4)$ & & & \\
\hline$\# 4$ & $\cdot$ & • & & & - & • & $\checkmark(\mathrm{D} 2 * \mathrm{M} 4)$ & & & & \\
\hline$\# 11$ & & & & $\cdot$ & & & $x(\mathrm{D} 1 * \mathrm{M} 4)$ & & & & $\checkmark(\mathrm{D} 1 * \mathrm{M} 4)$ \\
\hline$\# 12$ & & & & $\cdot$ & & & $x(\mathrm{D} 1 * \mathrm{M} 4)$ & & & & $\checkmark(\mathrm{D} 1 * \mathrm{M} 4)$ \\
\hline$\# 14$ & & • & & & & & & & & & $x(\mathrm{D} 1 * \mathrm{M} 1)$ \\
\hline$\# 15$ & • & - & - & & & & & & $x(\mathrm{D} 2 * \mathrm{M} 1)$ & $\boldsymbol{J} / \boldsymbol{x}(\mathrm{D} 2 * \mathrm{M} 1)$ & $\boldsymbol{J} / \boldsymbol{x}(\mathrm{D} 2 * \mathrm{M} 1)$ \\
\hline$\# 16$ & • & • & $\cdot$ & & & & $\checkmark(\mathrm{f}) / x(\mathrm{D} 1 * \mathrm{M} 1)$ & & & & $x(\mathrm{D} 1 * \mathrm{M} 1)$ \\
\hline$\# 17$ & $\cdot$ & • & & & & & $x(\mathrm{D} 1 * \mathrm{M} 2)$ & & & & \\
\hline$\# 20$ & & & & $\cdot$ & & & & & $\checkmark(\mathrm{f} ; \mathrm{D} 1 * \mathrm{M} 2)$ & & $x(f ; D 1 * M 2)$ \\
\hline \#21 & & & & - & & & & & & $x(\mathrm{D} 2 * \mathrm{M} 2)$ & \\
\hline
\end{tabular}


Note. $\boldsymbol{V}=$ (partial) mediation, $\boldsymbol{X}=$ no mediation, $\mathrm{f}=$ result only applies to females, $\mathrm{m}=$ result only applies to males. Empirical conclusiveness score between brackets. 
Table 3.

Studies examining psychological constraints and resources as a mediating pathway between SES and BMI (pathway B).

\begin{tabular}{|c|c|c|c|c|c|c|c|c|c|c|c|c|}
\hline \multirow[t]{3}{*}{ Study } & \multicolumn{6}{|c|}{ SES indicator } & \multicolumn{6}{|c|}{ Psychological factor } \\
\hline & \multirow[b]{2}{*}{$\stackrel{\mathscr{\Xi}}{\stackrel{\Xi}{\Xi}}$} & \multirow{2}{*}{ :气气̆ } & \multirow{2}{*}{ 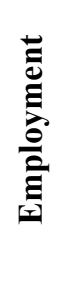 } & \multirow{2}{*}{ 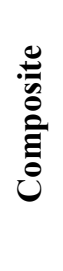 } & \multirow{2}{*}{ 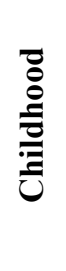 } & \multirow{2}{*}{ 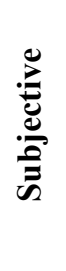 } & \multicolumn{2}{|c|}{ Stress } & \multicolumn{4}{|c|}{ Other } \\
\hline & & & & & & & $\begin{array}{c}\text { Perceived stress } \\
\text { or negative affect }\end{array}$ & Composite & $\begin{array}{c}\text { Time } \\
\text { perspective }\end{array}$ & $\begin{array}{c}\text { Eating } \\
\text { motivation / } \\
\text { control }\end{array}$ & Personal control & Big 5 \\
\hline$\# 1$ & & $\cdot$ & $\bullet$ & & & & & & & $\checkmark / x(\mathrm{D} 1 * \mathrm{M} 2)$ & & \\
\hline$\# 3$ & & & & • & & & $x(\mathrm{D} 1 * \mathrm{M} 4)$ & & & & & \\
\hline$\# 4$ & - & - & & & $\bullet$ & - & $\boldsymbol{J} / \boldsymbol{x}(\mathrm{D} 2 * \mathrm{M} 4)$ & & & & $\checkmark(\mathrm{D} 2 * \mathrm{M} 4)$ & $\boldsymbol{J} / \boldsymbol{x}(\mathrm{D} 2 * \mathrm{M} 4)$ \\
\hline$\# 5$ & - & - & • & & & & $\boldsymbol{J}(\mathrm{D} 1 * \mathrm{M} 1)$ & & & & & \\
\hline$\# 6$ & • & $\bullet$ & - & & • & & & & & & & $\boldsymbol{J} / \boldsymbol{x}(\mathrm{D} 2 * \mathrm{M} 1)$ \\
\hline$\# 7$ & & & • & & & & & & & $\boldsymbol{V} / \boldsymbol{x}(\mathrm{f} ; \mathrm{D} 1 * \mathrm{M} 2)$ & & \\
\hline$\# 8$ & $\cdot$ & & & & & & $\boldsymbol{V} / \boldsymbol{x}(\mathrm{f} ; \mathrm{D} 1 * \mathrm{M} 3)$ & & & & & \\
\hline$\# 9$ & & • & & & & & & & $x(\mathrm{D} 1 * \mathrm{M} 2)$ & & & \\
\hline$\# 10$ & & & & & & & $\checkmark(\mathrm{D} 2 * \mathrm{M} 2)$ & & & & & \\
\hline$\# 11$ & & & & - & & & & $x(\mathrm{D} 1 * \mathrm{M} 4)$ & & & & \\
\hline
\end{tabular}


Table 3 continued.

\begin{tabular}{|c|c|c|c|c|c|c|c|c|c|c|c|c|}
\hline \multirow[t]{3}{*}{ Study } & \multicolumn{6}{|c|}{ SES indicator } & \multicolumn{6}{|c|}{ Psychological factor } \\
\hline & \multirow[b]{2}{*}{$\stackrel{\mathscr{\Xi}}{\stackrel{\Xi}{\Xi}}$} & \multirow{2}{*}{ : } & \multirow{2}{*}{ 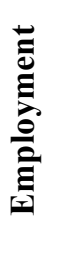 } & \multirow{2}{*}{ 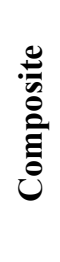 } & \multirow{2}{*}{ 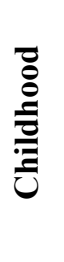 } & \multirow{2}{*}{ 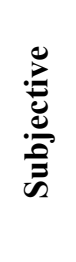 } & \multicolumn{2}{|c|}{ Stress } & \multicolumn{4}{|c|}{ Other } \\
\hline & & & & & & & $\begin{array}{l}\text { Perceived stress } \\
\text { or negative affect }\end{array}$ & Composite & $\begin{array}{c}\text { Time } \\
\text { perspective }\end{array}$ & $\begin{array}{c}\text { Eating } \\
\text { motivation / } \\
\text { control }\end{array}$ & Personal control & Big 5 \\
\hline$\# 12$ & & & & $\bullet$ & & & & $x(\mathrm{D} 1 * \mathrm{M} 4)$ & & & & \\
\hline$\# 13$ & & • & • & & • & & $x(\mathrm{D} 2 * \mathrm{M} 2)$ & & & & & \\
\hline$\# 14$ & & - & & & & & $x(\mathrm{D} 1 * \mathrm{M} 1)$ & & & & & \\
\hline$\# 16$ & • & - & • & & & & $x(\mathrm{D} 1 * \mathrm{M} 1)$ & & & & & \\
\hline$\# 19$ & - & • & & & & & & & & & $x(\mathrm{D} 1 * \mathrm{M} 1)$ & \\
\hline$\# 20$ & & & & • & & & & & $\checkmark(\mathrm{f} ; \mathrm{D} 1 * \mathrm{M} 2)$ & & $\boldsymbol{V} / \boldsymbol{X}(\mathrm{f} ; \mathrm{D} 1 * \mathrm{M} 2)$ & \\
\hline \#22 & • & • & • & & & & $\checkmark(f ; D 1 * M 1)$ & & & & & \\
\hline
\end{tabular}


Table 4

Studies examining environmental and psychological factors as a mediating pathway between lower SES and obesity (pathway C).

Note. $\boldsymbol{\checkmark}=$ (partial) mediation, $\boldsymbol{X}=$ no mediation, $\mathrm{f}=$ result only applies to females, $\mathrm{m}=$ result only applies to males. Empirical conclusiveness score between brackets. 